Title:

\title{
2 Structural basis for RNA-duplex unwinding by the DEAD-box helicase DbpA
}

Author:

\section{Jan Philip Wurm}

Author Affiliations:

6 Institute of Biophysics and Physical Biochemistry, Regensburg Center for Biochemistry, University of Regensburg, 93053 Regensburg, Germany.

8 Corresponding Author:

Jan Philip Wurm, E-mail: jan-philip.wurm@ur.de, phone: +49-941-943-2495, ORCID: 0000-0003-

$10 \quad 0985-7273$

Keywords:

12 DEAD-box helicase, ribosome biogenesis, molecular mechanism, RNA, NMR spectroscopy 
14 DEAD-box RNA helicases are implicated in most aspects of RNA biology, where these enzymes unwind short RNA duplexes in an ATP-dependent manner. During the central step of the unwinding

16 cycle, the two domains of the helicase core form a distinct closed conformation that destabilizes the RNA duplex, which ultimately leads to duplex melting. Despite the importance of this step for the unwinding process no high resolution structures of this state are available. Here, we employ nuclear magnetic resonance spectroscopy and X-ray crystallography to determine structures of the DEAD-

20 box helicase DbpA in the closed conformation, complexed with substrate duplexes and singlestranded unwinding product. These structures reveal that DbpA initiates duplex unwinding by

22 interacting with up to three base-paired nucleotides and a 5' single-stranded RNA duplex overhang. These high-resolution snapshots, together with biochemical assays, rationalize the destabilization of

24 the RNA duplex and are integrated into a conclusive model of the unwinding process.

\section{Introduction}

26 RNA molecules are involved in numerous cellular processes and their correct folding is often critical for function. RNA helicases that act as RNA chaperons, resolve misfolded RNA structures

28 and rearrange RNA-protein complexes consequently being essential for cellular survival (Jarmoskaite and Russell, 2014).

30 The largest family of RNA helicases in eukaryotes is represented by DEAD-box proteins (FairmanWilliams et al., 2010). These enzymes unwind short RNA duplexes (up to 12-16 base pairs) in a non-processive and ATP-dependent manner. The functional core of DEAD-box helicases consists of two RecA like domains (termed RecA_N and RecA_C for the N- and C-terminal domains,

34 respectively). The two domains are connected by a short, flexible linker and undergo large conformational changes during the unwinding cycle (Fig. 1a) (Linder and Jankowsky, 2011; Putnam 36 and Jankowsky, 2013). In the apo-state, the helicase core adopts an open conformation, where the 
two RecA domains tumble independently (Sun et al., 2014; Theissen et al., 2008; Wurm, 2020) and

36 where ATP can bind to the RecA_N domain (Mallam et al., 2012; Samatanga and Klostermeier, 2014). Binding of substrate RNA - in addition to ATP - induces the formation of a distinct closed conformation (Sun et al., 2014; Theissen et al., 2008), where ATP is sandwiched between the two domains and one of the RNA strands is bound to a bipartite active site, formed by both core 40 domains (Sengoku et al., 2006). RNA binding to the active site leads to the destabilization of the RNA duplex and spontaneous dissociation of the unbound RNA strand (Rogers et al., 1999; Yang et

42 al., 2007). The ATPase activity of DEAD-box helicases is greatly increased in the closed conformation. Upon ATP hydrolysis the helicase core returns to the open conformation (Theissen et

44 al., 2008), while ADP and the single-stranded RNA product dissociate due to the dissolution of the active site. ATP binding is therefore sufficient for unwinding, with ATP hydrolysis mainly serving to

46 release the helicase from unwound ssRNA (Liu et al., 2008). In addition to the productive unwinding cycle described above, DEAD-box helicases are prone to futile cycles, which occur when ATP is hydrolyzed prior to dissociation of the RNA duplex (Fig. 1a). These futile cycles increase sharply for longer, more stable duplexes due to decreased duplex dissociation rates

50 (Putnam and Jankowsky, 2013).

Several structures of DEAD-box helicases in the closed state, bound to single-stranded RNA

52 (ssRNA) and non-hydrolyzable ATP analogs were determined in the last 15 years (Chen et al., 2020; Collins et al., 2009; Del Campo and Lambowitz, 2009; Montpetit et al., 2011; Ngo et al., 2019; Ren

54 et al., 2017; Sengoku et al., 2006; Wong et al., 2016). Consequently, such structures correspond to the product-bound state following duplex unwinding and prior to ATP hydrolysis. The structures 56 revealed a conserved ssRNA binding mode (Figure 1-figure supplement 1), where the bipartite, active site of the helicase core interacts with the sugar and phosphate backbone of six single58 stranded nucleotides (nt). The RNA adopts a bent conformation due to the interaction between the RNA backbone and several highly conserved sequence motifs within the helicase core domains. 
60 This RNA conformation strongly differs from the canonical A-form helical conformation and is thus incompatible with duplex formation (Russell et al., 2013). In agreement with the sequence-

62 independent unwinding activity of DEAD-box helicases, no interactions are formed between the active site and RNA bases. In contrast to this wealth of structural information for the product-bound

64 state, a structure of the closed-conformation complexed with double stranded RNA (dsRNA) substrate and ATP analog, is still missing. It is therefore unclear how the central step of the

66 unwinding process - namely, the destabilization of the RNA duplex - is achieved at the molecular level.

68 A major challenge in the structural characterization of the destabilized duplex state lies in the trapping of this inherently unstable state in a homogeneous conformation. This is further

70 complicated by the lack of sequence-specificity that facilitates binding in differing registers to the RNA. In order to overcome these challenges we selected the E. coli DEAD-box helicase DbpA for

72 structural studies. DbpA possesses a C-terminal RNA recognition motif (RRM) (Wang et al., 2006) in addition to the helicase core and, we recently demonstrated that this RRM domain is stably

74 anchored to the RecA_C domain (Fig. 1b) (Wurm et al., 2021). DbpA is involved in ribosome maturation (Sharpe Elles et al., 2009) and is recruited to the nascent ribosome by a specific, high76 affinity interaction between the RRM and hairpin 92 (HP92) of the 23S rRNA (Fig. 1b) (Diges and Uhlenbeck, 2001; Hardin et al., 2010). Binding of HP92 is necessary for the helicase activity of

78 DbpA, as a direct interaction between RRM-bound HP92 and the RecA_N domain strongly stabilizes - and thereby enables - formation of the closed conformation (Wurm et al., 2021). A 80 substrate duplex linked to HP92 is therefore recruited to DbpA with high affinity and can also be efficiently unwound. Meanwhile, attachment onto HP92 locks the substrate duplex in a well-defined

82 position relative to the active site of the helicase core consequently stabilizing the helicase/substrate complex. 
84 In this study we employ nuclear magnetic resonance (NMR) spectroscopy to identify suitable ATP analogs and RNA constructs that enable trapping of DbpA in complex with a destabilized duplex.

86 Based on these results we solved crystal structures of DbpA in the closed state, where the active site of the helicase core interacts with two different substrate RNAs: an RNA hairpin loop and a

88 ss/dsRNA junction. In addition, we determined the DbpA structure bound to a ssRNA product. These structures can be readily integrated into a model of the unwinding cycle, where interactions

90 between helicase and the ss/dsRNA junction rationalize how DbpA achieves the RNA duplex destabilization and promotes unwinding.
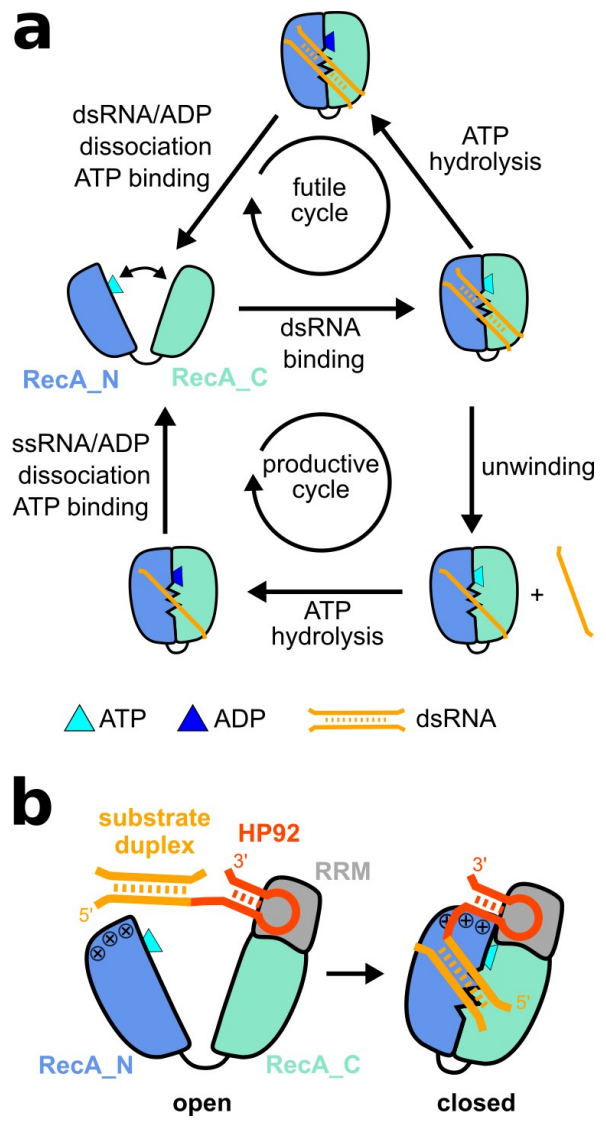

92 Fig. 1: Unwinding cycle of DEAD-box helicases and activation of DbpA by HP92 RNA. (a) Schematic diagram of futile cycles (top) and productive unwinding cycles (bottom) of DEAD-box

94 helicases. The helicase core (RecA_N domain blue, RecA_C domain cyan) alternates between an open conformation in the apo or ATP bound state and a closed conformation in the presence of ATP

96 and RNA. (b) Domain orientation of DbpA in the open (left) and closed state (right). The Cterminal RRM (grey) orients HP92 (red) such that the stem of HP92 forms favorable interactions 
98 with a positively charged patch (indicated by + signs) on the RecA_N domain in the closed state. This stabilizes the closed state and enables the recruitment of the substrate duplex (orange, located 5' to HP92) to the active site of the helicase core.

\section{Results}

\section{A hairpin RNA substrate in combination with $\mathrm{ADP} / \mathrm{BeF}_{3}$ traps the destabilized duplex state.}

In order to gain insights into the molecular mechanism that underlies duplex destabilization by

104 DbpA during unwinding, we set out to identify conditions that trap the helicase when complexed with an unwinding intermediate. Since ATP binding is sufficient for unwinding, with ATP non-hydrolyzable ATP analogs that support the formation of the closed state, based on their ability

108 to fuel duplex unwinding by DbpA during single-turnover unwinding assays. To allow for unwinding by DbpA, the RNA construct included HP92 together with the substrate duplex

110 consisting of nine bp (Fig. 2a). From the four investigated ATP analogs (ADPNP, ADPCP, ATPץS and $\left.\mathrm{ADP} / \mathrm{BeF}_{3}\right)$, only $\mathrm{ATP} \gamma \mathrm{S}\left(\mathrm{k}_{\mathrm{obs}} 0.04 \pm 0.01 \mathrm{~min}^{-1}\right)$ and $\mathrm{ADP} / \mathrm{BeF}_{3}\left(\mathrm{k}_{\mathrm{obs}} 0.10 \pm 0.01 \mathrm{~min}^{-1}\right)$

112 supported unwinding of the RNA substrate on a similar timescale as ATP $\left(\mathrm{k}_{\text {obs }} 0.43 \pm 0.02 \mathrm{~min}^{-1}\right)$. Interestingly, $\mathrm{ATP} \gamma \mathrm{S}$ was hydrolyzed during the unwinding process (Figure 2 - figure supplement 1)

114 and is therefore not suitable for trapping the destabilized duplex over extended periods. Based on these results we identified $\mathrm{ADP} / \mathrm{BeF}_{3}$ as a suitable ATP analogue for further investigations.

116 To enforce trapping of the destabilized duplex by DbpA and to prevent the dissociation of the RNA duplex, we made use of an RNA construct (hp-HP92 RNA) containing a hairpin structure with a

118 stable UUCG tetraloop as the substrate (Fig. 2B). This substrate hairpin prevents the dissociation of the destabilized duplex. To probe formation of the closed state, we performed NMR titrations using

120 deuterated DbpA that is ${ }^{1} \mathrm{H},{ }^{13} \mathrm{C}$-labeled at the methyl-groups of Ile, Leu, Met, Val, Ala (ILMVA) and that yields high-quality methyl-group spectra ((Wurm et al., 2021); Figure 2 - figure supplement 2). 
122 Binding of the hp-HP92 RNA substrate to DbpA can be monitored based on changes (chemical shift perturbations CSPs) of the position of the methyl-group signals (Fig. 2b, Figure 2 - figure

124 supplement 2). In the absence of ATP, RNA binding induces large CSPs for residues that belong to the RRM, though only minimally affecting signals from the RecA core domains (Fig. 2c, upper 126 graph). This demonstrates that only the RRM of DbpA interacts with HP92 of the hp-HP92 RNA, and that no specific contacts between the substrate duplex and the core domains are formed in the 128 absence of ATP analog. In line with this finding, essentially identical CSPs are elicited by an RNA construct (termed ss-HP92) that contains a single-stranded region instead of the substrate duplex

130 (Fig. 2c, bottom graph, note that differences in CSPs ( $\triangle \mathrm{CSPs}$ ) are shown, Figure 2 - figure supplement 3).

132 During the next step we added the identified ATP analogue $\mathrm{ADP} / \mathrm{BeF}_{3}$ to the $\mathrm{DbpA} / \mathrm{hp}-\mathrm{HP92}$ complex. This leads to large CSPs within the helicase core domains (Fig. 2d, 2e top graph, Figure 2

134 - figure supplement 4). As we have shown previously (Wurm et al., 2021) these CSPs mark the formation of the DbpA closed state. Similarly, the closed state is also formed upon addition of $\mathrm{ADP} / \mathrm{BeF}_{3}$ to the DbpA/ss-HP92 complex (Figure 2 - figure supplement 5). Interestingly, the DbpA spectra for the closed state reveal several distinct differences between ss-HP92 and hp-HP92 RNA 138 complexes (Fig. 2e, bottom graph, Figure 2 - figure supplement 5) and these differences cluster in the vicinity of the helicase core active site (Fig. 2f). We reasoned that these differences arise from

140 the interaction with the intact substrate duplex in the hp-HP92 complex rather than the singlestranded region in the ss-HP92 RNA suggesting that the substrate duplex is not completely

142 unwound in the hp-HP92/DbpA complex.

To verify the presence of the substrate duplex in the closed state we turned to $1 \mathrm{D}{ }^{1} \mathrm{H}$ imino proton

144 spectra (Fig. 2g,h). Only imino protons of nucleotides that are involved in stable base pairs give rise to observable signals in such spectra. To confirm the presence of the substrate hairpin we 146 concentrated on the three uridines within this hairpin (labeled U1 to U3 in Fig. 2g,h). Binding of 
148 increased molecular weight of the complex. This shows that there is no (or only a highly transient) interaction between DbpA and the substrate hairpin of the hp-HP92 RNA. By contrast, the

150 guanosine residues of the HP92 stem (labeled G4-G6 in Fig. 2g,h) show clear CSPs due to direct interaction with the RRM of DbpA (Hardin et al., 2010; Wurm et al., 2021). Addition of ADP/BeF 3

152 to the DbpA/RNA complex leads to formation of the closed state of DbpA and induces large shifts for essentially all imino proton signals (Fig. 2i). This provides clear evidence for a direct interaction

154 between DbpA and the substrate hairpin within the closed state. At least 7-8 of the nine imino proton signals are still visible indicating that the substrate hairpin is still largely intact when bound

156 to the active site of DbpA. This is supported by ${ }^{1} \mathrm{H}^{15} \mathrm{~N}-\mathrm{HMQC}$ spectra of uridine ${ }^{15} \mathrm{~N}$-labeled hpHP92 RNA (Fig. 2i). In these spectra only imino signals of based paired uridines are detectable. The

158 spectra show two uridine imino signals in the closed state, which must originate from the substrate duplex as we have shown previously that the uridine imino signals of HP92 are not detectable under

160 this measurement conditions (Wurm et al., 2021). We tentatively assign the signals to the central uridines of the substrate hairpin (U2/U3).

162 In summary, these results demonstrate that the $\mathrm{DbpA} / \mathrm{hp}-\mathrm{HP} 92 / \mathrm{ADP} / \mathrm{BeF}_{3}$ complex represents a trapped unwinding intermediate where the mostly-intact duplex of the substrate hairpin interacts 164 with the active site of the helicase core. 

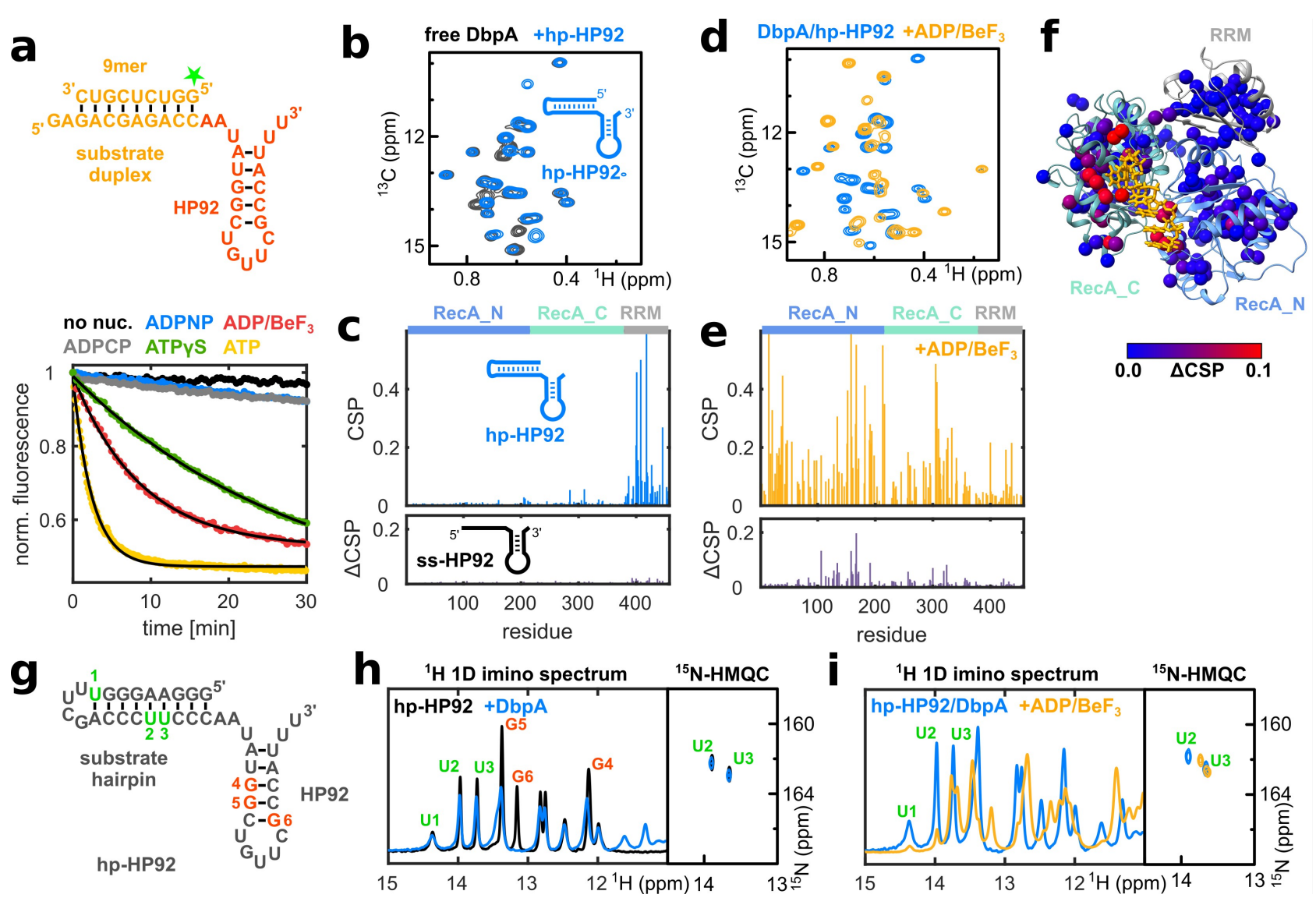

Fig. 2: The DbpA/hp-HP92/ADPBeF 3 complex represents a trapped unwinding intermediate.

(a) Fluorescence based unwinding assays in the presence of different ATP analogs. A 5' fluorescein (green star) labeled 9mer RNA is hybridized to an RNA containing HP92 (top). Unwinding can be followed by a decrease in fluorescence intensity (bottom). Mono-exponential fits to the fluorescence time traces are shown in black for ATP, $\mathrm{ADP} / \mathrm{BeF}_{3}$ and $\mathrm{ATP} \gamma \mathrm{S}$. (b) Ile region of methyl TROSY spectra of ILMVA-labeled DbpA in the free state (black) and bound to hp-HP92 RNA (blue). (c) Sequence plots of CSPs induced by binding of the hp-HP92 RNA (top) and differences

172 between CSPs ( $\triangle$ CSPs) induced by binding of the ss-HP92 RNA and the hp-HP92 (bottom). DbpA domains are indicated at the top. (d) Methyl TROSY spectra of DbpA/hp-HP92 complex prior to

174 (blue) and after addition of $\mathrm{ADP} \mathrm{BeF}_{3}$ (orange). (e) Sequence plots of CSPs induced by binding of $\mathrm{ADP} / \mathrm{BeF}_{3}$ to the DbpA/hp-HP92 RNA complex (top) and $\triangle \mathrm{CSPs}$ between binding of $\mathrm{ADP} / \mathrm{BeF}_{3}$ to

176 the ss-HP92/DbpA and to the hp-HP92/DbpA complexes (bottom). (f) $\Delta$ CSPs from (e) plotted onto a model of the closed state of DbpA bound to ssRNA ((Wurm et al., 2021), red large $\Delta$ CSPs, blue small $\Delta$ CSPs). The ssRNA is shown in orange. (g) Sequence of hp-HP92 RNA. Nucleotides with assigned imino proton signals are numbered and shown in red (HP92) or green (substrate hairpin). 
RNA prior to (black) and after addition of DbpA (blue). (i) Same spectra as in (h), but for the hpHP92/DbpA complex prior to (blue) and after addition of $\mathrm{ADP} / \mathrm{BeF}_{3}$ (orange).

\section{Structure of the hairpin RNA bound to the active site of DbpA}

184 To understand how duplex destabilization by DbpA is achieved on a structural level, we solved the crystal structure of the $\mathrm{DbpA} / \mathrm{hp}-\mathrm{HP} 92 / \mathrm{ADP} / \mathrm{BeF}_{3}$ complex to a resolution of $3.2 \mathrm{~A}$ (Fig. 3a, Figure

1863 - figure supplement 1). Surprisingly, a 2:2 DbpA:RNA complex is formed in the crystal. Each DbpA molecule interacts with the HP92 of one RNA molecule (via the RRM) and with the substrate

188 hairpin (via the core domains' active site) of the other RNA. The two hairpins of each RNA molecule stack co-axially and HP92 is elongated by 2 bp, which are formed between the 3' 190 overhang of HP92 and the linker between HP92 and the substrate hairpin (nt 23-25, see Figure 3 figure supplement 2 for details). Since the good quality of the NMR spectra (Fig. 2d) strongly argued against a 2:2 complex with a molecular weight $>120 \mathrm{kDa}$, we investigated the oligomeric state of the $\mathrm{DbpA} / \mathrm{hp}-\mathrm{HP} 92 / \mathrm{ADP} \mathrm{BeF}_{3}$ complex in solution, using size exclusion chromatography

194 (SEC) experiments (Fig 3c). The experiments show that addition of $\mathrm{ADP} / \mathrm{BeF}_{3}$ to the $\mathrm{DbpA} / \mathrm{hp}-$ HP92 complex leads to the formation of two species: A minor population of a larger species, which

196 would be compatible with a 2:2 complex and a major population of a more compact species, which we assign to the 1:1 complex. These results indicate that 1:1 and 2:2 complexes co-exist in solution.

We conclude that our NMR experiments predominantly report on the major population of the 1:1 complex, whereas the minor population of the 2:2 complex was crystallized. Notably, the SEC and NMR experiments were conducted at similar concentrations, with higher concentrations used for crystallization trials, which is expected to increase the population of the 2:2 complex. Importantly, 
204 interactions in the crystal structure between DbpA and the RNA hairpins are relevant in solution.

The interactions between HP92 and the RRM of DbpA are basically identical to the interactions

observed for a homologous RRM/HP92 complex that was previously published (Hardin et al., 2010) (Figure 3 - figure supplement 3) and we hereby focus on the interaction between the substrate

208 hairpin and the active site of the helicase core (Fig. 3d, Figure 3 - figure supplement 4a). The split active site interacts with 6 nt (numbered 1-6 in Fig. 3d) of the hairpin. The first 3 nt belong to the

210 loop of the substrate hairpin, whereas nt 4-6 are part of the stem. Due to interaction with the active site, the first base pair of the stem (formed between the adenosine at position 4 and the opposing

212 uridine) is distorted in comparison to a regular AU base pair, and consequently only forms one hydrogen bond. Conversely, the cytosines in position 5 and 6 form regular GC base pairs with the

214 opposing strand. All six bases in the binding site show continuous base stacking interactions.

Next, we compared the RNA conformation within the hp-HP92/DbpA complex with the canonical

216 ssRNA product-bound state of other DEAD-box helicases (exemplified by the VASA helicase (Sengoku et al., 2006)) The conformation of nt 1-4 in both structures is basically identical. The

218 main differences reside in the conformation of nt 5 and 6 . In the VASA structure the bases of nt 5 and 6 are rotated by $90^{\circ}$ relative to the DbpA structure and consequently their conformation is not

220 compatible with duplex formation. In contrast to the known, product-bound states, our structure thus demonstrates that DbpA is able to bind a ss/dsRNA junction that contains a 5' ssRNA overhang

222 of 3 nt, whereby the 3 nt overhang and the first 3 nt of the duplex interact with positions 1-3 and 4-6 of the active site. We propose that the crystallized conformation represents a trapped unwinding 224 intermediate that captures the interaction between a ds/ssRNA junction and DbpA during unwinding. 

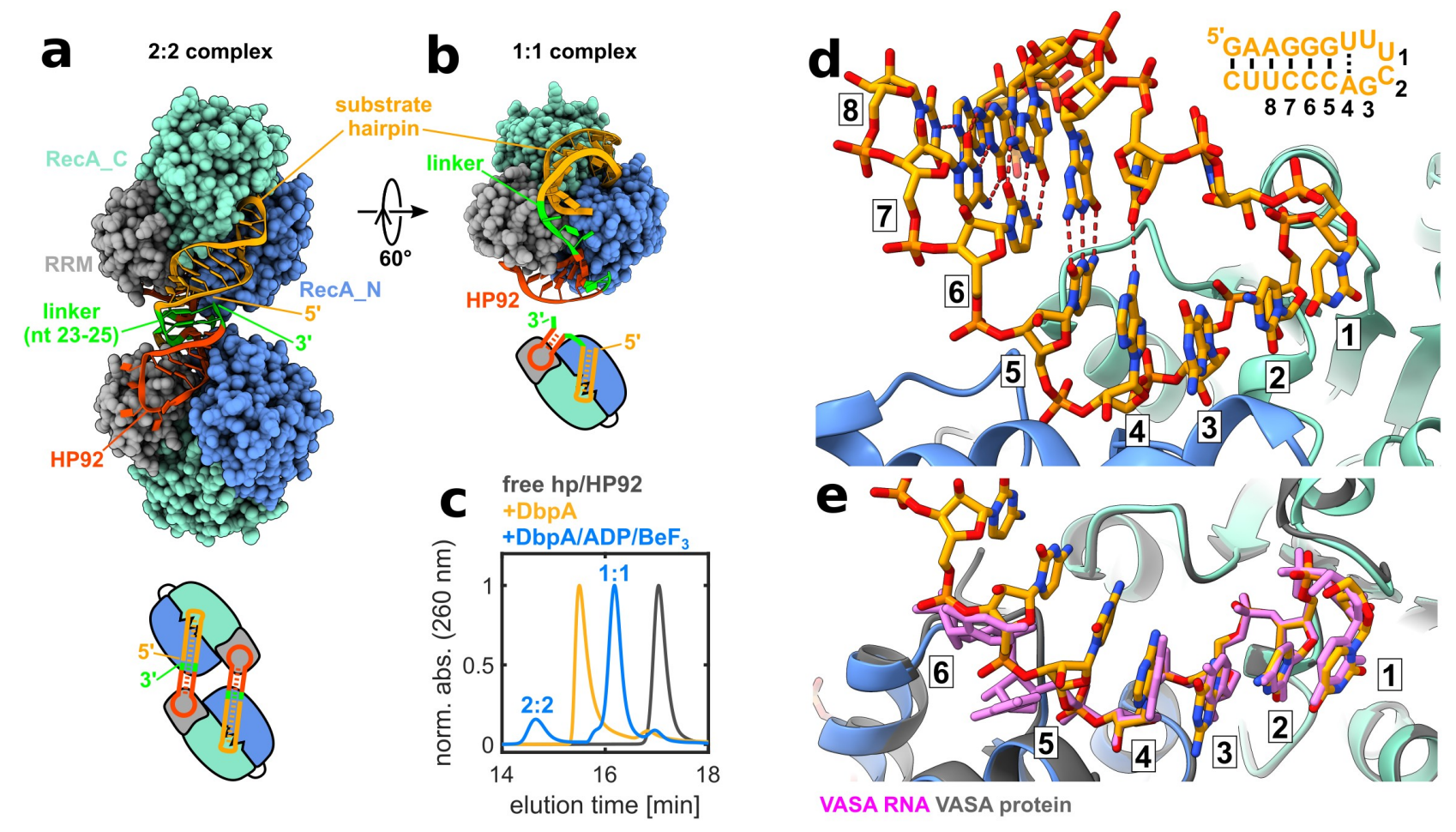

226 Fig. 3: Structure of the hp-HP92/DbpA complex in the closed state. (a) Overall structure (top) and schematic diagram (bottom) of the complex between two DbpA molecules (chains A/B) and two hp-HP92 RNAs (chains F/G), as observed in the crystal. HP92 (red), the substrate hairpin (orange) and the $3 \mathrm{nt}$ linker that base pairs with the 3' overhang of HP92 (green) are shown in ribbon representation. The RecA_N (blue), RecA_C (cyan) and RRM (grey) domains of DbpA are shown in sphere representation. (b) Model of the 1:1 complex obtained by connecting HP92 and the substrate hairpin bound to one DbpA molecule by a flexible $3 \mathrm{nt}$ linker (green). (c) SEC chromatograms of free hp-HP92 (black), the hp-HP92/DbpA complex (orange) and the hp-HP92/DbpA/ADP/BeF 3 (blue) complex. (d) Close-up of the interaction between substrate hairpin (chain F, orange) and the active site of the helicase core (chain B, RecA_N blue, RecA_C cyan). The nucleotides that interact with the active site are numbered 1-6. The substrate hairpin is shown in the upper-right, with identical numbering. The distorted base pair between the adenosine in position 4 and the opposite uridine is indicated by a dashed line. (e) Comparison between the substrate hairpin bound to DbpA (only nt 1-7 are shown for clarity) and the complex between a $6 \mathrm{nt}$ ssRNA (pink) and the DEAD-box helicase VASA (grey) (PDB ID 2db3). 


\section{Structure of a ss/dsRNA junction bound to the active site of DbpA}

242 To exclude the possibility that the observed RNA conformation is influenced by the short loop of the substrate hairpin, we crystallized DbpA with a permuted RNA construct (termed ds-HP92) that

244 contains a ss/dsRNA junction with a 3 nt 5' overhang instead of the hairpin. To this end, the two coaxially stacking helices of the hp-HP92 RNA were fused, which places the 5' and 3' ends at the position of the loop of the substrate hairpin (Fig 4a, Figure 3 - figure supplement 2c). The complex crystallized as a 2:2 complex similar to the hp-HP92 RNA (Fig 4a, Figure 3 - figure supplement 2d) and the structure was determined to a resolution of $3.0 \AA$ (Figure 3 - figure supplement 1 ). Since fusion of the helices prevents the substrate duplex from folding back onto the active site of the same DbpA molecule, the 2:2 complex is also the major species in solution (Fig. 4b). In the structure, the 3 nt 5 ' overhang and the first 3 nt of the substrate duplex are bound to the active site in positions 1-3 and 4-6, respectively (Fig. 4c, Figure 3 - figure supplement 4b). The DbpA/RNA interactions are virtually identical to the ones observed in the hairpin structure, with the exception that the first base

254 pair of the duplex (formed between the adenosine at position 4 and the opposing uridine) is not distorted. The distortion in the first base pair of the hp-HP92 RNA thus most likely originates from

256 the strain in the short loop of the substrate hairpin.

To evaluate whether an extended duplex with base-paired nucleotides in positions 2 and 3 could interact with DbpA in a similar manner, we modeled two additional nucleotides at the 3' end of the RNA in an A-form helix conformation (Fig. 4d, green residues). The model reveals that both nucleotides of the extended helix would severely clash with $\alpha$-helix $\alpha 7$ of the RecA_N domain. This indicates that: i) a 5' single-stranded region of 3 nt is necessary for the interaction of duplex RNA

262 with DbpA; ii) only nucleotides in positions 4-6 can be part of a duplex, whereas positions 1-3 are not compatible with dsRNA. In summary, these results enforce the notion that DbpA interacts with

264 a ds/ssRNA junction during the unwinding process, where nucleotides in position 1-3 are singlestranded and nucleotides 4-6 can be part of a duplex. 

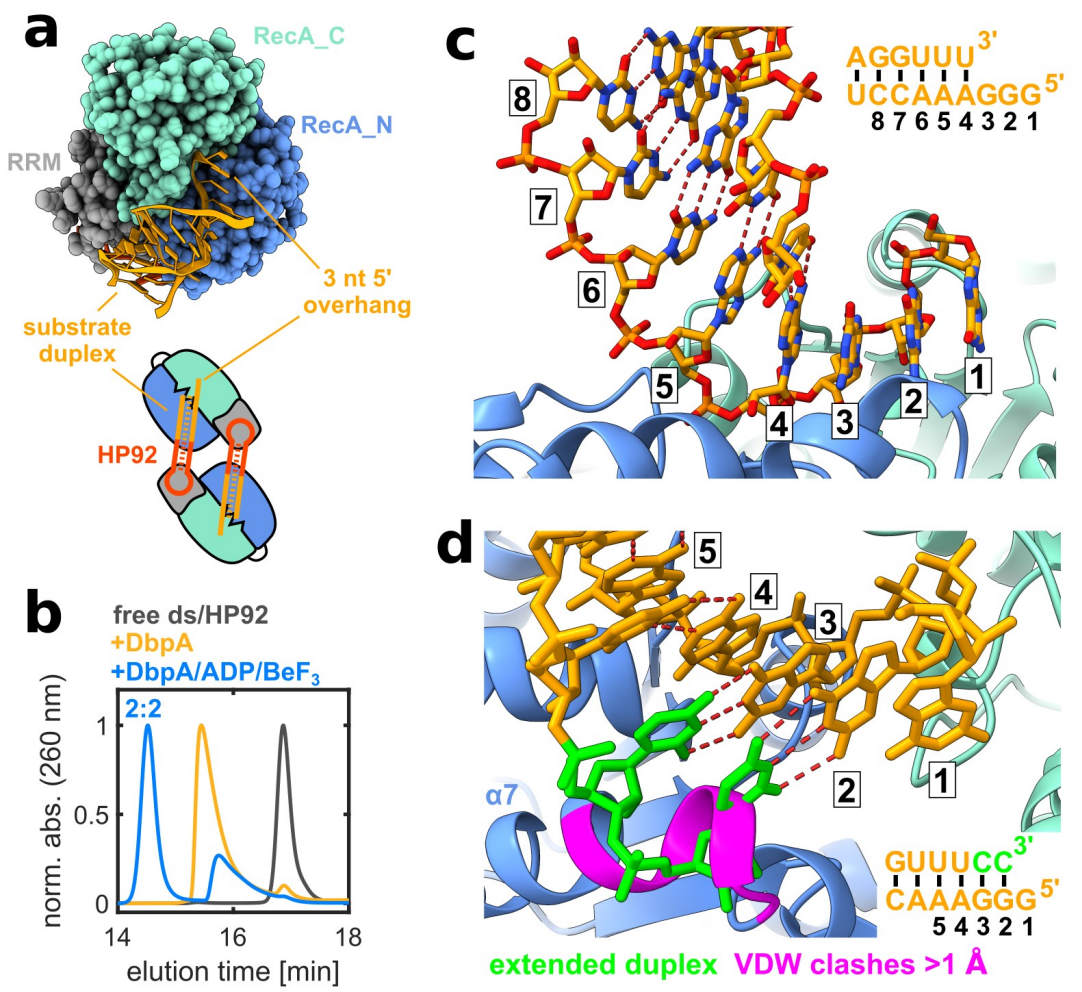

266 Fig. 4: Structure of the ds-HP92/DbpA complex in the closed state. (a) Interaction of the substrate duplex including a 3 nt 5' overhang with the active site of the helicase core. For clarity, only the substrate duplex (chain D) and one DbpA molecule (chain B) are shown (top). Schematic diagram of the 2:2 complex observed in the crystal (bottom). (b) SEC chromatograms of free ds-

270 HP92 (black), the ds-HP92/DbpA complex (orange) and the ds-HP92/DbpA/ADP/BeF 3 (blue) complex. (c) Close-up of the interaction between the substrate duplex (chain D, orange) and the

272 active site of the helicase core (chain B, RecA_N blue, RecA_C cyan). The nucleotides that interact with the active site are numbered 1-6. The substrate duplex is shown in the upper-right, with

274 identical numbering. (d) Extension of the duplex by addition of 2 nt at the 3' end (green) leads to severe clashes with $\alpha$-helix $\alpha 7$ of the RecA_N domain. Residues that show van der Waals clashes $>$

$2761 \AA$ with the RNA are shown in pink.

\section{Structure of the ssRNA product bound to the active site of DbpA}

278 To complete the picture of the unwinding cycle of DbpA, we aimed to also gain insights into the ssRNA product-bound state after duplex unwinding. To this end we solved the structure of DbpA in 
complex with $\mathrm{ADP} / \mathrm{BeF}_{3}$ and an RNA construct termed ss-HP92 (Figure 3 - figure supplement 2e).

282 This RNA contains a single-stranded region 5' to HP92 that interacts with the active site of the helicase core (Fig. 5a). Again crystallization resulted in a 2:2 RNA:DbpA complex (Figure 3 -

284 figure supplement 2f) and SEC experiments show that the 2:2 complex is predominant in solution (Fig. 5b). Similar to the ds-HP92 and hp-HP92 complexes, each DbpA molecule interacts with 286 HP92 of one RNA via the RRM and with the single-stranded region of the other RNA via the core domains. Three 2:2 complexes are present in the asymmetric unit. All of them display highly similar structures. The main differences reside in the conformation of the single-stranded region of the RNA. Three RNAs (chains G, H and L) adopt the same canonical ssRNA binding mode as observed 290 in other DEAD box helicases (conformation 1, Fig. 5C, Figure 3 - figure supplement 4c). The bases of nt 1-4 show a continuous stacking interaction, whereas the bases of nt 5 and 6 are rotated by $90^{\circ}$

292 relative to nt 1-4. In the other three RNAs (chains C, D and K) all six bases show a continuous stacking interaction (conformation 2, Fig. 5d, Figure 3 - figure supplement 4d). This continuous

294 base stacking and the overall RNA conformation resembles the ds-HP92/DbpA complex structure (Figure 5 - figure supplement 1). Conformation 2 could therefore represent a snapshot of the RNA 296 conformation immediately following duplex dissociation, before the RNA transitions into conformation 1.

298 These results demonstrate that DbpA conforms to the canonical ssRNA product binding mode observed for other DEAD-box helicases, but also suggest a notable plasticity in its ssRNA 300 interaction mode. A comparison between the ds-HP92 and ss-HP92 RNA bound structures and the VASA/RNA complex shows that the interaction with nt 1-4 is essentially identical in all structures

302 (Figure 5 - figure supplement 2) and that the differences reside mainly in the interaction of nt 5 and 6 with the helicase core (Fig. 5e). In the canonical binding mode, the conserved R378 of VASA 304 forms hydrogen bonds with the ribose of nt 5 and the phosphate group of nt 6 . In the DbpA structures, the corresponding R132 is slightly repositioned, but forms similar interactions with nt 5 

favorably interact with duplex as well as with ssRNA at positions 4-6.
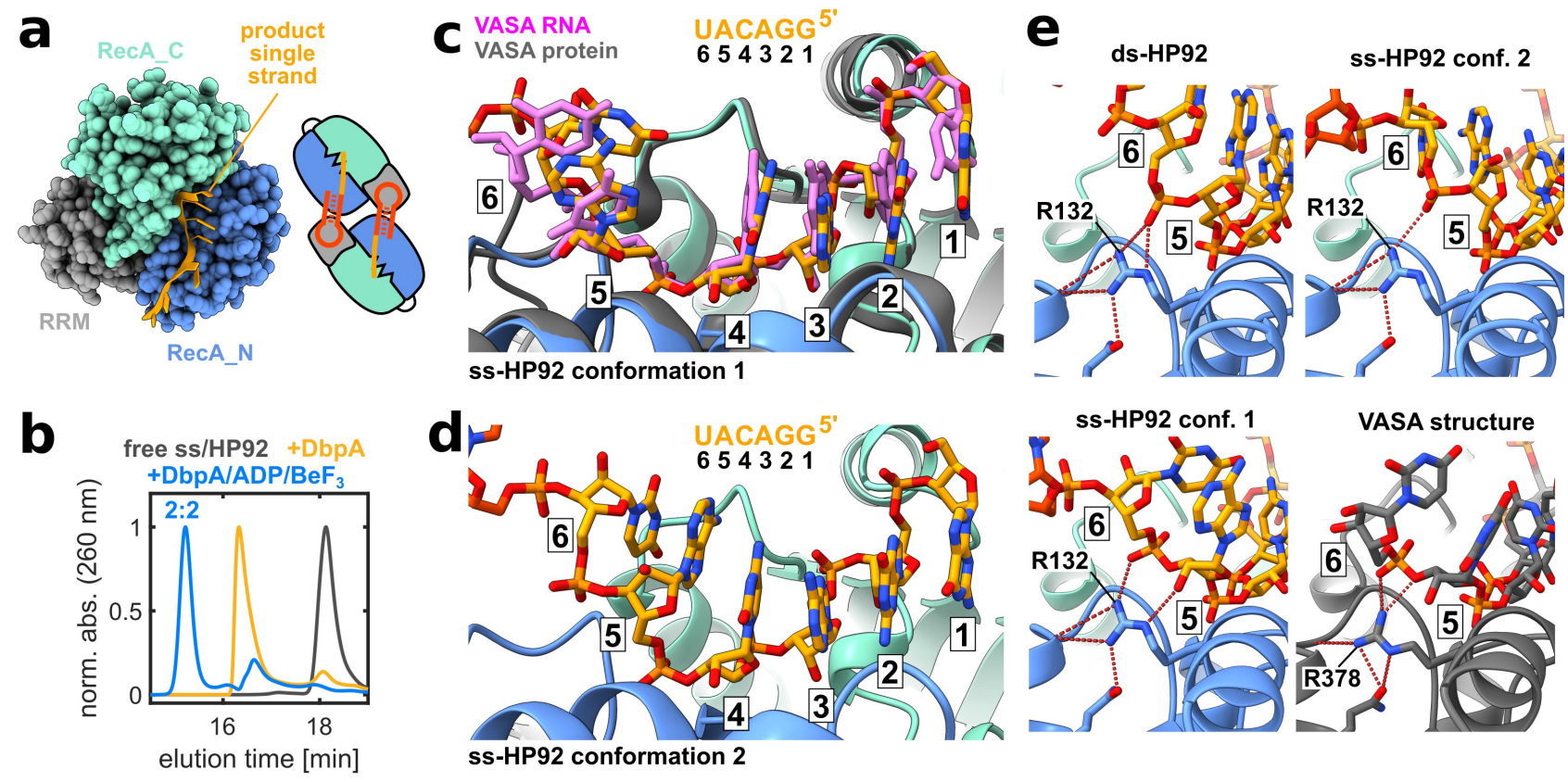

308 Fig. 5: Structure of the ss-HP92/DbpA complex in the closed state. (a) Interaction of the ssRNA with the active site of the helicase core. For clarity, only the ssRNA (chain L) and one DbpA molecule (chain I) are shown (left). Schematic diagram of the 2:2 complex observed in the crystal (right). (b) SEC chromatograms of free ss-HP92 (black), the ss-HP92/DbpA complex (orange) and the ss-HP92/DbpA/ADP/BeF 3 complex (blue). (c) Close-up of the interaction between the ssRNA region (chain L, orange) in conformation 1 and the active site of the helicase core (chain I, RecA_N

314 blue, RecA_C cyan). For comparison, the complex between a 6 nt RNA (pink) and the DEAD-box helicase VASA (grey) (PDB ID 2db3) is shown. The nucleotides that interact with the active site are numbered 1-6. The ssRNA sequence is shown on top with identical numbering. (d) Close up of the interaction between the ssRNA region (chain C, orange) in conformation 2 and the active site of the helicase core (chain A, RecA_N blue, RecA_C cyan). (e) Comparison of the interactions between nucleotides in position 5 and 6 for DbpA and VASA. The top row and the bottom-left panel show complexes between DbpA and ds-HP92 and ss-HP92 in conformation 1 and 2. The lower-right panel shows the VASA/ssRNA complex (PDB ID 2db3). Hydrogen bonds formed by R132 (DbpA) or the corresponding R378 (VASA) are indicated by dashed-red lines. 


\section{Activity assays support an initial interaction with a ss/dsRNA junction during unwinding}

324 In summary, the structures of the ds-HP92 and ss-HP92 complexes suggest the following model of duplex unwinding from a 5' overhang. DbpA initially binds to the ss/dsRNA junction of the duplex,

326 where 3 nt of the 5' overhang interact with position 1-3 and the first 3 nt of the duplex with position 4-6. Breathing of the duplex ends, which takes place on the ms timescale (Snoussi and Leroy, 328 2001), thus leads to ss-HP92 conformation 2, and subsequently to ss-HP92 conformation 1 . The ssHP92 conformation 1 prevents duplex re-formation, thereby destabilizing the remaining duplex and accelerating its spontaneous dissociation.

To support this model, we performed single turnover unwinding assays with RNA constructs that

332 contain a 9-bp duplex and a 5' ssRNA overhang of 0, 2, 5 or 8 nt (Fig. 6a). The observed duplex unwinding rates (Fig. 6b) increase for overhangs of 0 and 2 nt from $0.20 \mathrm{~min}^{-1}$ to $0.42 \mathrm{~min}^{-1}$ and

334 then decline for longer 5' overhangs of $5\left(0.32 \mathrm{~min}^{-1}\right)$ and $8 \mathrm{nt}\left(0.21 \mathrm{~min}^{-1}\right)$. These results can be rationalized based on our model. The 5' overhang of 0 nt shows the lowest unwinding rate, as

336 formation of the closed state depends on the presence of a 5' single-stranded region. In the absence of a 5' ssRNA overhang, this single-stranded region is only transiently formed by fraying of the 338 terminal base pairs. Elongation of the overhang to 2 nt increases unwinding, as the overhang facilitates the formation of the closed state and only fraying of the terminal base pair is necessary.

340 Longer overhangs are expected to facilitate the formation of the closed state even further, but also increase the risk of unproductive interactions, where DbpA would only bind to the ssRNA

342 overhang, which would not destabilize the duplex region.

This finding is corroborated by ATPase assays with identical RNA constructs including the 9-bp

344 duplex (Fig. 6c, red symbols). ATP hydrolysis requires formation of the closed state and ATPase rates therefore report on the efficiency of closed state formation. The observed ATPase rates increase proportionally with 5 ' overhang length from $2.3 \mathrm{~min}^{-1}$ for the 0 nt overhang to $52 \mathrm{~min}^{-1}$ for the $8 \mathrm{nt}$ overhang, confirming that longer overhangs facilitate the formation of the closed state. 
Consequently, constructs with longer 5' overhangs require additional ATP hydrolysis events for

352 support unwinding of duplexes with long 5' overhangs, since DbpA should be trapped predominantly within unproductive closed states (note that a 5' overhang of 2 nt was used in the

354 helicase assays in Fig. 2a). This is experimentally verified in unwinding assays for the 8 nt 5' overhang, where unwinding is strongly reduced compared to the 2 nt overhang (Fig. 6e). These

356 results and the increased ATPase rate for longer 5' overhangs indicate that DbpA does not favor the interaction with the ss/dsRNA junction over the interaction with the ssRNA 5' overhang. To test

358 this, we performed ATPase assays in the absence of the 9mer RNA, for the RNA carrying the 2 nt 5 ' overhang (Fig. 6c, grey symbols). This leads to a 10.4-fold increase in the ATPase rate and indicates 360 that formation of the closed state is even more favorable for a ssRNA substrate, compared to a ss/dsRNA junction. In summary, the observed helicase and ATPase rates are in good agreement with

362 a model whereby DbpA preferentially forms the closed state upon interaction with a 5' ssRNA overhang or a ssRNA/duplex junction, as observed in structures of the ss-HP92 and dsHP92 364 complexes. 

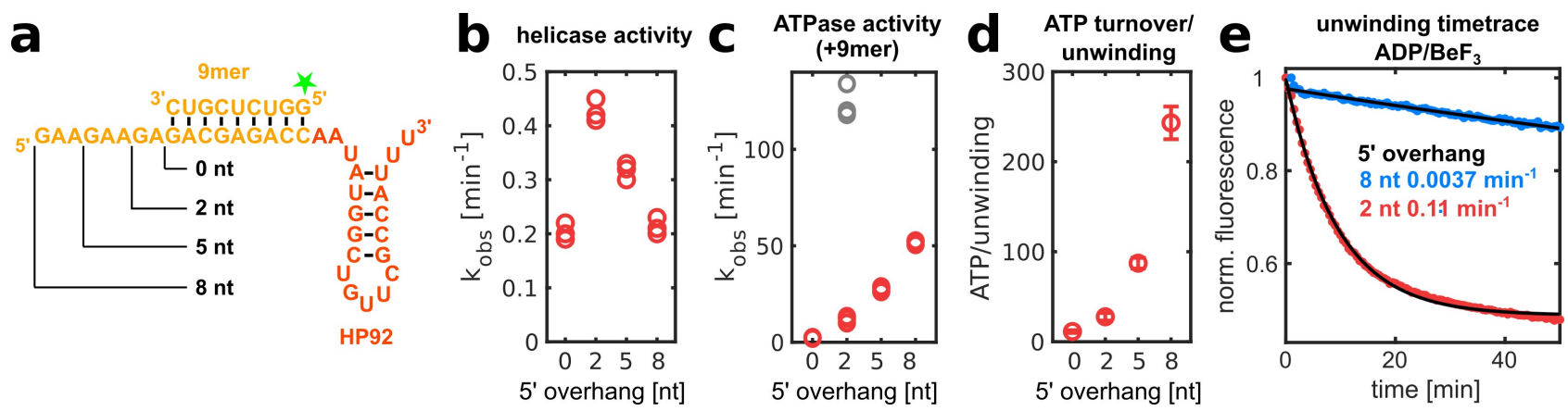

Fig. 6: The length of the ssRNA 5' overhang influences helicase and ATPase activity of DbpA.

(a) RNA constructs used for activity assays. The substrate duplex (orange) is located 5' to HP92 (red). The varying length of the 5' overhangs is indicated. For helicase assays, the 9mer RNA contained a fluorescein label at the 5' end (indicated by a green star). (b) Unwinding rates observed in single-turnover experiments are plotted versus the 5' overhang length. Results from three measurements are shown. (c) ATPase turnover rates are plotted versus the 5' overhang length. Rates were determined in the absence (grey) and presence of the 9mer RNA (red). Results from three

372 measurements are shown. (d) The number of hydrolyzed ATP molecules for each unwinding event are plotted versus the 5' overhang length. The values represent mean and standard deviation

374 calculated from the experiments shown in panels b and c. (e) Single-turnover unwinding of RNA constructs with a 5' overhang of two (red) or eight nt (blue) in the presence of $\mathrm{ADP} / \mathrm{BeF}_{3}$ is followed by fluorescence intensity measurements. Exponential fits to fluorescence time traces are shown in black and the unwinding rates obtained from the fits are given.

\section{Transient active site formation and substrate RNA binding in the absence of ATP}

Finally, we sought to gain direct insights into the initiation of the unwinding process, namely, the

formation of the closed state. Closing of the DbpA/RNA complex is inherently inefficient as three bodies (the two RecA domains and substrate RNA) require assembly in the correct orientation. This raises the question whether the substrate RNA binds to a pre-formed active site (where the two RecA domains assemble initially) or whether the substrate RNA initially interacts with one of the

RecA domains prior to the active site assembly. To test for active site pre-formation we performed paramagnetic relaxation enhancement (PRE) experiments using RNA that corresponds to isolated 
392 HP92 (Fig. 7a, Figure 7 - figure supplement 1a) and that carries a nitroxide spin label at the 3' end. The spin label induces a PRE that leads to a strong decrease of the methyl-group NMR signals in its

394 vicinity, which can be readily quantified and allow for the detection of sparsely populated states (Clore et al., 2007). Upon binding of the spin labeled HP92, we observe the expected PREs close to the HP92 binding site on the RRM. Additional PREs are observed on top of the RecA_N domain (Fig. 7a, Figure 7 - figure supplement 1a) indicating that this region of the RecA_N domain also approaches the spin label. Since close contacts between the RecA_N domain and HP92 are only found in the closed state of the enzyme (Fig. 7a), these results clearly indicate that DbpA transiently adopts the closed state in the presence of HP92. It would be interesting to explore whether the closed state is also formed in the absence of HP92. However, due to the nine native cysteine residues in DbpA we were not able to selectively introduce a spin label in the protein.

404 To test for interactions between the substrate duplex and the RecA domains, we repeated the PRE experiments with a hp-HP92 RNA construct that carries a spin label in the loop of the substrate hairpin (Fig. 7b, Figure 7 - figure supplement 1b). In the absence of ATP analog, the PREs for this RNA construct are distributed over a large surface on the RRM and RecA_C domains, indicating that the substrate hairpin only transiently interacts with these domains, and samples a large set of different conformations. The largest PREs are observed for a positively charged region on the RRM

410 surrounding L455 (Fig. 7c). This positively charged patch is located remotely from the active site, and its function is currently unknown. It was speculated to be important for RNA interactions in the

412 context of the pre-ribosome (Hardin et al., 2010) and most likely attracts the substrate hairpin in the PRE experiments due to its positive charge. More importantly, the residues from the RecA_N 414 domain with the largest PREs (M114 and M161) and the residues with large PREs on the RecA_C domain are in close contact solely in the closed conformation (Fig 7b). This indicates that DbpA 416 also transiently adopts the closed conformation in the presence of hp-HP92 and thereby 
418 domain, large PREs are also found for I355 from the RecA_C domain. Both residues are located in proximity of the spin label when the substrate hairpin is bound to the active site in the closed state

420 (Fig. 7b). These PREs therefore suggest that the transiently formed, closed state interacts with the substrate hairpin in a similar manner as observed in the structure of the stably-closed 422 hp-HP92/DbpA complex. In line with this finding, large PREs are observed for M161 and I355 upon stable formation of the closed state by addition of $\mathrm{ADP}^{\mathrm{BeF}} \mathrm{B}_{3}$ (Fig. 7d, Figure 7 - figure

424 supplement 1c). These PREs are also in good agreement with our structure of hp-HP92/DbpA complex and thereby provide an independent validation the this structure.

426 Overall, the PRE experiments demonstrate the transient formation of the closed state in the presence of HP92 and hp-HP92 RNAs, and also suggest that the substrate hairpin interacts with the 428 transiently-formed active site in a similar manner as observed in the hp-HP92/DbpA structure. This hints at a pathway for the formation of the active state, where the closed state is transiently formed 430 and, consequently, the substrate duplex is recruited to the pre-formed active site in a second step. 
a

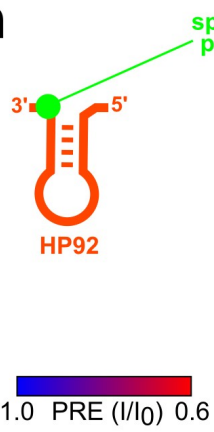

1.0 PRE $\left(\mathrm{I} / \mathrm{I}_{0}\right) 0.6$
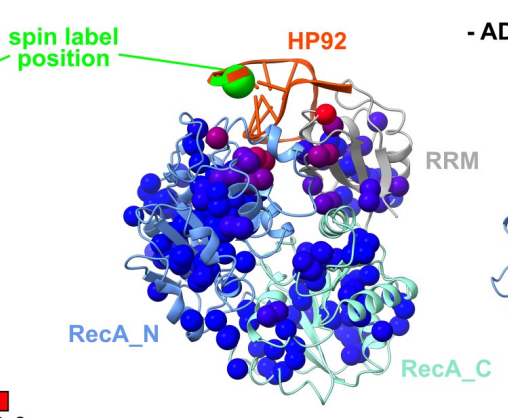

closed conformation

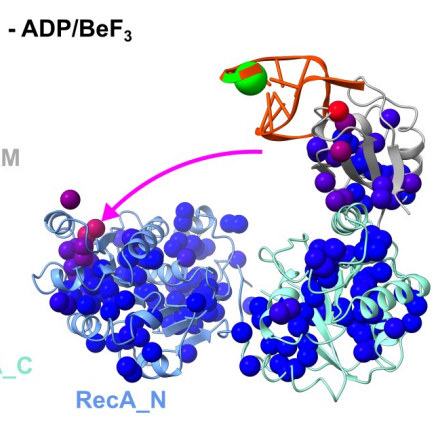

open conformation
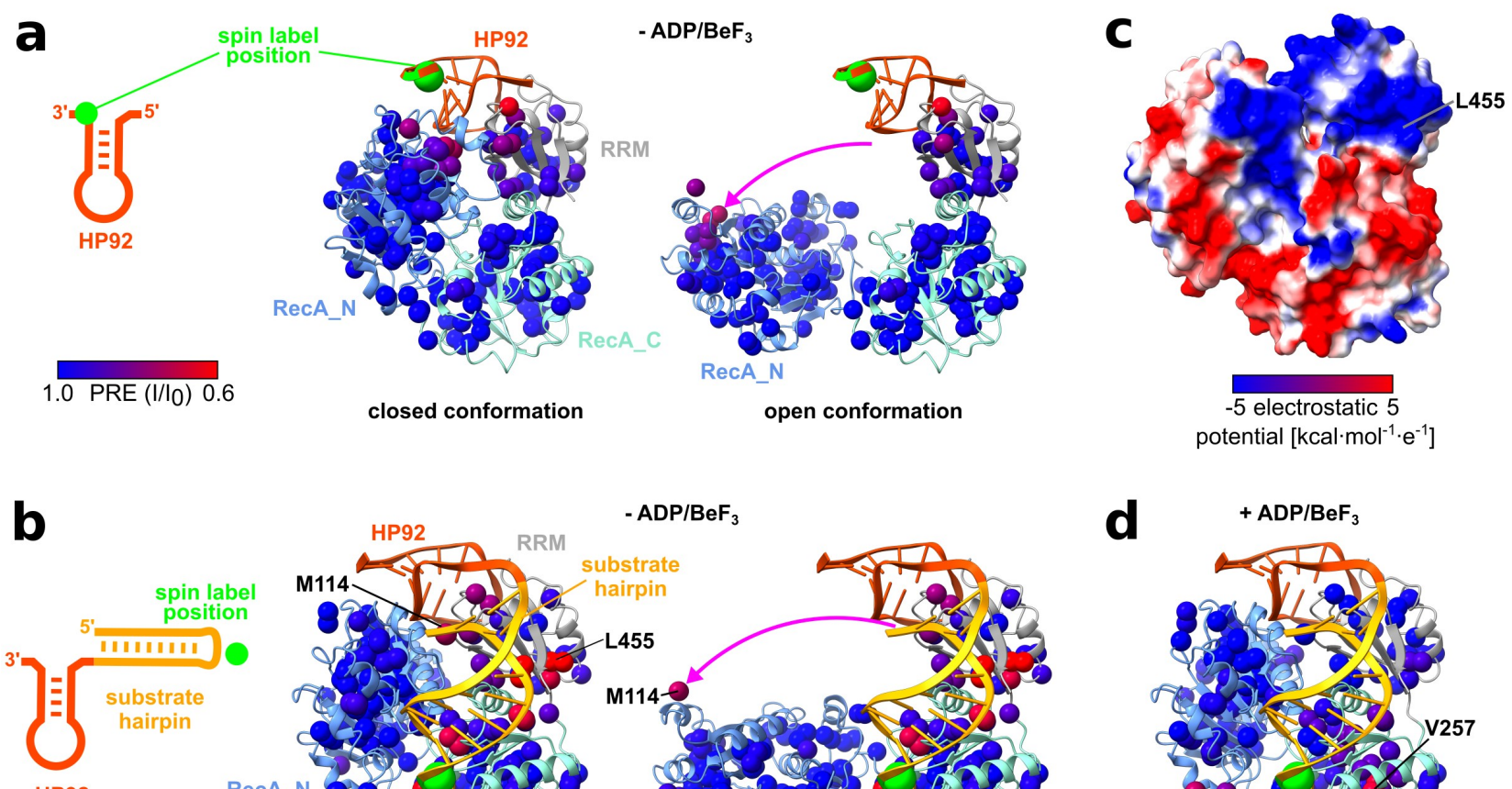

HP92

1.0 PRE $\left(\mathrm{I} / \mathrm{I}_{0}\right) \quad 0.6$

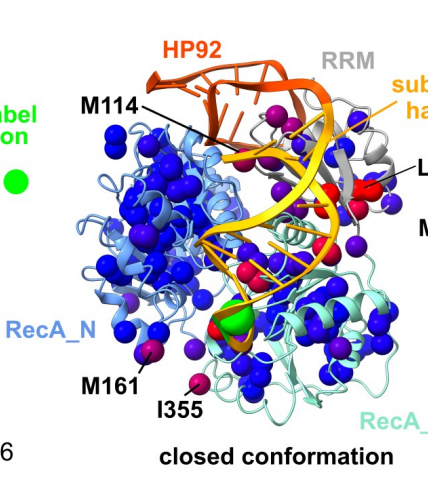

$-\mathrm{ADP}^{-\mathrm{BeF}_{3}}$

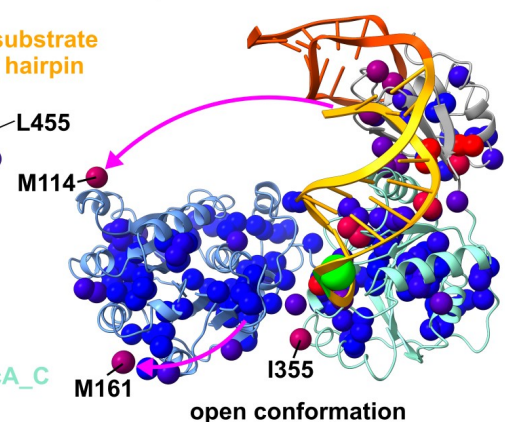

d

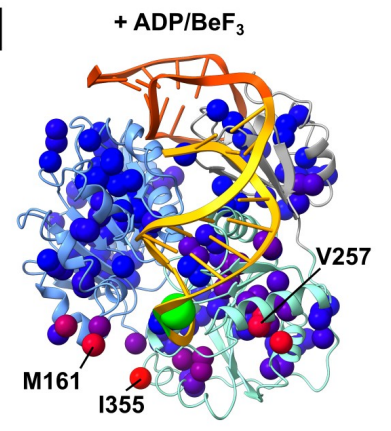

closed conformation

Fig. 7: DbpA transiently samples the closed state in the absence of ATP. (a) PRE experiments

432 were performed with spin labeled HP92 RNA and ILMVA-labeled DbpA in the absence of $\mathrm{ADP} / \mathrm{BeF}_{3}$. The RNA construct is shown on the left. The position of the 4-thiouridine residue that

434 carries the nitroxide spin label is indicated by a green circle. The methyl-groups of DbpA are colored according to the decrease in signal intensity, due to spatial proximity of the spin label from

436 blue (no effect) to red (strong reduction). The closed conformation (left structure) and an arbitrary open conformation (right structure) are depicted. The pink arrow indicates the re-orientation of the

438 RecA_N domain between the two structures. The C1' atom of the spin labeled 4-thiouridine is shown as a green sphere. (b) PRE experiments with an hp-HP92 RNA containing a spin label in the

440 loop of the substrate hairpin (green circle) (left). Methyl-groups are colored as in (a) for the closedconformation (left structure) and for an arbitrary open conformation (right structure). The pink

442 arrows indicates the re-orientation of the RecA_N domain. The methyl-groups of M114 and M161 that exhibit the largest PREs in the RecA_N domain are labeled. The RNA is shown in the

444 conformation observed in the DbpA/hp-HP92 complex, where the substrate interacts with the active site of the helicase core. (c) DbpA in the closed conformation colored according to electrostatic surface potential (blue = negative, red = positive). $(\mathbf{d})$ PRE experiments with identical RNA as in (b), but in the presence of $\mathrm{ADP} / \mathrm{BeF}_{3}$. Methyl-groups are colored as in (a) and DbpA is shown in the closed conformation. 


\section{Discussion}

450 The crystallographic snapshots of the unwinding intermediates that we determined in this study fill a major gap in our understanding of the unwinding process of DEAD-box helicases and rationalize

452 how the destabilization of the RNA duplex in the closed state is achieved. The structures can be readily integrated into a model of the unwinding process (Fig. 8): Prior to binding of the substrate

454 duplex, DbpA mainly populates an open state, whereby the RecA_N domain tumbles independently from the other two domains. This open state, however, transiently adopts the closed-conformation.

456 In the first step (1), the RNA duplex is recruited to this transiently-formed, closed-conformation. DbpA initially binds to 3 nt of the 5 ' overhang and the first 3 nt of the substrate duplex, as depicted

458 in the ds-HP92 complex structure (Fig. 4). Breathing of the duplex ends in the active site (step 2), which takes place on the $\mu$ s-ms timescale (Snoussi and Leroy, 2001), leads to conformation 2 of the ss-HP92 complex (Fig. 5d). In this conformation, all residues still exhibit a continuous base stacking. Subsequently, in step (3), a transition to the canonical ssRNA product conformation (as observed in conformation 1 of the ss-HP92 complex) (Fig. 5c) prevents re-formation of the 3 base pairs. This strongly destabilizes the remaining duplex and increases the dissociation rate for the

464 unbound RNA strand (step 4). The number of destabilized base pairs predicted based on these considerations is also in fair agreement with the number obtained from functional assays for the DEAD-box helicases eIF4A and Ded1 (2-3 and 4-5 base pairs, respectively (Raj et al., 2019; Rogers et al., 1999)).

468 Importantly, this model depicts only one of several different unwinding pathways that are compatible with our results. DbpA forms the closed state even more efficiently in the presence of 470 ssRNA compared to the ss/dsRNA junction (Fig. 6c). It is therefore very likely that it can also bind more distal to the duplex such that only 1 or 2 nt of the duplex interact with the active site of the

472 helicase core. Regarding blunt-end duplexes, fraying of the duplex ends will expose the 5' ssRNA overhang that is necessary for binding. Moreover, in our experiments the attachment of the substrate 
472 duplex to HP92 enforces the interaction with the duplex end that is distant from the HP92 attachment site and prevents interaction with the proximal duplex end that carries a 3' overhang.

474 Our results therefore only provide insights into unwinding from the distant duplex end that carries the 5' ssRNA overhang.

476 For most DEAD box helicases, the unwinding activity strongly increases with 3' and with 5' ssRNA overhangs relative to blunt end duplexes (Linder and Jankowsky, 2011), indicating that DEAD box

478 helicases can also effectively initiate unwinding from 3' ssRNA overhangs. This must proceed through a different mechanism, which might be analogous to the one described here and would involve binding to a ss/dsRNA junction with a 3' ssRNA overhang. In this case, the duplex region would bind to positions 1-3, which are mainly formed by the RecA_C domain, and the 3' ssRNA 482 overhang would interact with positions 4-6. This notion is supported by the structure of the isolated RecA_C domain of the DEAD-box helicase Mss116 in complex with an RNA duplex, which shows 484 that duplex binding to positions 1-3 is also possible (Mallam et al., 2012).

Interestingly, our ATPase assays with increasing 5' overhangs indicate no specificity of DbpA for 486 the ss/dsRNA junction over ssRNA, with 5' ssRNA overhangs of increasing length being detrimental to the unwinding process. This is in agreement with previous reports on DbpA (Henn et 488 al., 2010) and a similar observation has been made for the DEAD-box helicase eIF4A (Andreou et al., 2019). This finding supports a model where DEAD-box helicases act as ATP-fueled ssRNA

490 binding proteins, rather than dsRNA-specific helicases. In this scenario, unwinding would be the result of stochastic binding to ss/dsRNA junctions, rather than a process that is targeted toward 492 RNA duplexes. In line with this proposed lack of duplex-specificity, most DEAD-box helicases show strongly increased ATPase activity in the presence of ssRNA (Putnam and Jankowsky, 2013),

494 indicating that interaction with a duplex is generally not necessary for the formation of the closed state. In addition, several DEAD-box helicases have been shown to act as ssRNA clamps (Ballut et 
496 al., 2005; Xiol et al., 2014) or in the remodeling of RNA/protein complexes (Bowers et al., 2006; Tran et al., 2007) and these two processes are unrelated to the interaction with dsRNA. In line with 498 prior suggestions (Liu et al., 2008), we therefore favor a simple model, where the functions of DEAD-box helicases are explained by ATP-coupled, high-affinity ssRNA (or ss/dsRNA junction)

500 binding.

In summary, our results for DbpA indicate that unwinding of duplexes with a 5' ssRNA overhang proceeds through binding of the helicase core to the 5' ss/dsRNA junction. The high conservation of the characteristic DEAD-box sequence motifs in DbpA (Figure 8 - figure supplement 1, (Putnam 504 and Jankowsky, 2013)), together with the similarity of the ssRNA product-bound structure (ss-HP92 conformation 1) to the canonical product-bound state of DEAD-box helicases (Fig. 5c) suggests that 506 our results can be generalized to other DEAD-box helicases. Nonetheless, in addition to the unwinding pathway via the 5' ss/dsRNA junction described here, several other pathways are possible and remain to be described. 


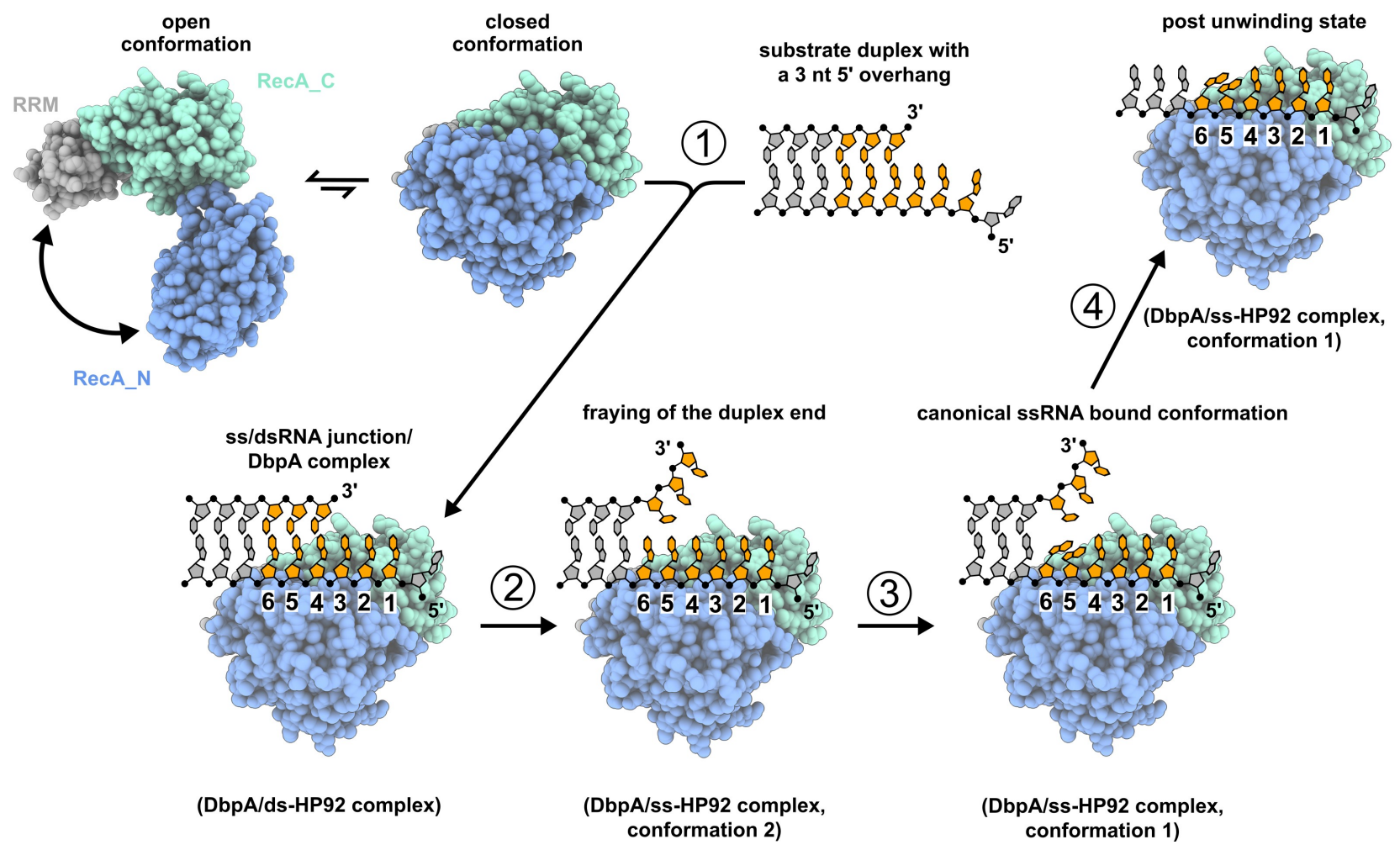

Fig. 8: Model of the unwinding mechanism for duplexes with 5' ssRNA overhangs. HP92 and

510 ATP are omitted for clarity. The nucleotides that interact with the active site of DbpA are colored orange. DbpA transiently adopts the closed-conformation in the absence of substrate RNA (upper-

512 left). (1) The closed-conformation binds to the ss/dsRNA junction, whereby nt 1-3 are singlestranded and nt 4-6 are still part of the duplex (as depicted in the structure of the DbpA/ds-HP92

514 complex). (2) Duplex breathing leads to a ssRNA-bound state with continuous base stacking (DbpA/ss-HP92 complex in conformation 2). (3) The nucleotides in positions 5/6 re-arrange to a

516 conformation that is incompatible with duplex formation (DbpA/ss-HP92 complex in conformation 1). (4) The loss of these three base pairs leads to dissociation of the upper RNA strand. 


\section{Materials and Methods}

\section{Protein expression and purification}

520 For DbpA expression the gene coding for full length DbpA (UniProt accession code P21693) was PCR amplified from E. coli BL21(DE3) genomic DNA and cloned into a pETM-11 plasmid that

522 codes for an N-terminal tobacco etch virus (TEV) protease cleavable hexahistidine tag. This plasmid was transformed into E. coli BL21(DE) codon plus cells. All growth media for protein

524 expression were supplemented with $50 \mathrm{mg} / \mathrm{L}$ kanamycin and $34 \mathrm{mg} / \mathrm{L}$ chloramphenicol. Cells were grown in $\mathrm{LB}$ medium at $37^{\circ} \mathrm{C}$ until an $\mathrm{OD}_{600}$ of $0.6-0.8$ was reached. For production of unlabeled

DbpA protein expression was induced at this stage by addition of $1 \mathrm{mM}$ IPTG, the cells were shifted to $25^{\circ} \mathrm{C}$ and harvested after $16-20 \mathrm{~h}$. For production of ILMVA methyl group labeled DbpA $1 \mathrm{~mL}$

528 of the LB culture was used to inoculate $25 \mathrm{~mL}$ of $\mathrm{H}_{2} \mathrm{O}$ based $\mathrm{M} 9$ minimal medium and cells were grown to an $\mathrm{OD}_{600}$ of $0.6-0.8$. Cells were harvested by centrifugation and used to inoculate $100 \mathrm{~mL}$ of $\mathrm{D}_{2} \mathrm{O}$ based M9-medium (containing $4 \mathrm{~g} / \mathrm{L}$ deuterated glucose) at an $\mathrm{OD}_{600}$ of 0.15 . Cells were grown over night at $37{ }^{\circ} \mathrm{C}$ and diluted $1 / 8$ with fresh $\mathrm{D}_{2} \mathrm{O}$ based $\mathrm{M} 9$ medium (containing $2 \mathrm{~g} / \mathrm{L}$

532 deuterated glucose) in the morning. Cells were grown at $37^{\circ} \mathrm{C}$ until an $\mathrm{OD}_{600}$ of 0.8 was reached. The culture was shifted to $25{ }^{\circ} \mathrm{C}$ and $60 \mathrm{mg}$ 2-Ketobutyric acid-(4- $\left.{ }^{13} \mathrm{C}, 3,3-\mathrm{d}_{2}\right), 100 \mathrm{mg}$ 2-Keto-3-

534 methyl-butyric acid-(dimethyl $\left.-{ }^{13} \mathrm{C}_{2}, \quad 3-\mathrm{d}\right)$ and $100 \mathrm{mg}$ L-methionine-(methyl- $\left.{ }^{13} \mathrm{C}\right)$ dissolved in $200 \mathrm{~mL}$ of $\mathrm{D}_{2} \mathrm{O}$ based M9 medium were added. After $45 \mathrm{~min} 100 \mathrm{mg}$ L-alanine-(methyl- $\left.{ }^{13} \mathrm{C}, 2-\mathrm{d}\right)$

536 was added and 15 min later protein expression was induced by addition of $1 \mathrm{mM}$ IPTG. Cells were harvested after $16-20 \mathrm{~h}$ and stored at $-20^{\circ} \mathrm{C}$.

538 For purification the cell pellets were resuspended in $20 \mathrm{~mL}$ of Buffer A (400 mM NaCl, $50 \mathrm{mM}$ sodium-phosphate, $\mathrm{pH}$ 7.4, $10 \mathrm{mM}$ imidazole) supplemented with $0.1 \%$ (v/v) triton-X-100,

$5401 \mathrm{mg} / \mathrm{mL}$ lysozyme and $0.1 \mathrm{mg} / \mathrm{mL}$ DNase I. Cells were lysed by sonication and cell debris was removed by centrifugation (30 $\mathrm{min}, 18000 \mathrm{~g}, 4^{\circ} \mathrm{C}$ ). The supernatant was applied to a gravity flow 542 Ni-NTA column equilibrated in buffer A. The column was washed with $20 \mathrm{~mL}$ of buffer A, $10 \mathrm{~mL}$ 
544 of $1 \mathrm{M} \mathrm{NaCl}, 25 \mathrm{mM}$ sodium-phosphate, $\mathrm{pH} 7.4$ and $20 \mathrm{~mL}$ of buffer $\mathrm{A}+10 \mathrm{mM}$ imidazole. DbpA was eluted with buffer B (400 mM NaCl, 300 mM imidazole, 50 mM sodium-phosphate, pH 7.4).

546 The N-terminal His-tag was removed by TEV protease digestion during dialysis against dialysis buffer (150 mM NaCl, 25 sodium-phosphate, $\mathrm{pH}$ 7.4, $1 \mathrm{mM} \mathrm{DTT}$ ) over night at $4{ }^{\circ} \mathrm{C}$. The TEV

548 protease contained an N-terminal hexahistidine tag and was removed by a second Ni-NTA column equilibrated in dialysis buffer. The column was washed with dialysis buffer. Flow through and wash

550 fractions were combined and $1 / 2$ volume of $60 \%(\mathrm{v} / \mathrm{v})$ glycerol solution was added. DbpA was further purified using a $5 \mathrm{ml}$ HiTrap HP Heparin column (GE healthcare) equilibrated in $100 \mathrm{mM}$

$552 \mathrm{NaCl}, 20$ mM HEPES, pH 7.3, 20 \% (v/v) glycerol. DbpA was eluted using a linear NaCl gradient from $100 \mathrm{mM}$ to $500 \mathrm{mM}$ over $50 \mathrm{ml}$. DbpA containing fractions were pooled, concentrated and

554 subjected to a size excluusion chromatography (SEC) step using a Superdex 75 16/600 column (GE healthcare) equilibrated in SEC buffer (125 mM NaCl, 25 mM HEPES, pH 7.3, 1 mM DTT). DbpA

556 concentrations were determined based on the $\mathrm{OD}_{280}$ using an extinction coefficient of $26900 \mathrm{M}^{-1} \mathrm{~cm}^{-}$

\section{RNA production}

RNAs were produced by in vitro transcription (IVTC) using homemade T7 polymerase (P266L 560 mutant (Guillerez et al., 2005)). Single stranded DNA oligonucleotides, to which a DNA oligonucleotide corresponding to the T7 promotor sequence was hybridized, were used as

562 templates. IVTCs were performed in 5-10 ml reactions containing $1 \mu \mathrm{M}$ template DNA, $4 \mathrm{mM}$ of each NTP, 15-50 mM $\mathrm{MgCl}_{2}$ (optimized for each RNA construct), $50 \mathrm{mM}$ Tris, pH 8.0, $1 \mathrm{mM}$ 564 spermidine, $5 \mathrm{mM}$ DTT, $0.01 \%(\mathrm{v} / \mathrm{v})$ triton X-100, $40 \mathrm{ug} / \mathrm{ml}$ T7 polymerase and were incubated at $37^{\circ} \mathrm{C}$ for 3 h. Subsequently, 50 mM EDTA, pH 8.0 was added and the RNA was precipitated by 566 addition of $0.7 \mathrm{vol}$ of isopropanol. RNAs were purified using a DNAPac 100 column $(22 \times 250$ $\mathrm{mm}$, Dionex) heated to $70{ }^{\circ} \mathrm{C}$. Buffers for purification contained $5 \mathrm{M}$ Urea, $20 \mathrm{mM}$ Tris, $\mathrm{pH} 8.0$ (pH 
568 adjusted at RT) and 0 (buffer A) or $2 \mathrm{M} \mathrm{NaCl}$ (buffer B). RNAs were eluted using linear gradients from 5-15 \% B to 20-40 \% B depending on the RNA construct at a flowrate of $10 \mathrm{ml} / \mathrm{min}$. Fractions

570 containing the desired RNA product were pooled and precipitated by addition of 1 vol of isopropanol and incubation at $-20^{\circ} \mathrm{C}$ for at least $1 \mathrm{~h}$. After centrifugation (8000 g, $\left.4{ }^{\circ} \mathrm{C}, 45 \mathrm{~min}\right)$ the

572 RNA pellet was washed with $75 \%$ (v/v) ethanol, dried and resuspended in $\mathrm{H}_{2} \mathrm{O}$. RNA concentrations were determined based on $\mathrm{OD}_{260}$. Extinction coefficients were calculated using the

574 OligoAnalyzer Tool (IDT). See Appendix 1 - table 1 for the sequences of the RNA constructs used in this study.

\section{NMR experiments}

All NMR experiments were conducted on Bruker $600 \mathrm{MHz}$ and $800 \mathrm{MHz}$ Avance Neo

578 spectrometers equipped with nitrogen $(600 \mathrm{MHz})$ or helium cooled (800 MHz) cryoprobes. MethylTROSY spectra were recorded using the SOFAST-HMQC pulse sequence (Schanda et al., 2005).

580 Measurements were performed at $25{ }^{\circ} \mathrm{C}$ in SEC buffer supplemented with $5 \%(\mathrm{v} / \mathrm{v}) \mathrm{D}_{2} \mathrm{O}$ for the lock. DbpA concentrations in titration experiments with ILMVA-labeled DbpA were 40-70 $\mu \mathrm{M}$ and

RNAs were added in 1.3 times excess over DbpA. For experiments where RNAs where titrated with DbpA, RNA concentrations were $100 \mu \mathrm{M}$ and unlabeled DbpA was added in 1.3 times excess over RNA. To form the ADP/BeF 3 bound state $2 \mathrm{mM} \mathrm{MgCl}_{2}, 2 \mathrm{mM} \mathrm{BeF}_{2}, 2 \mathrm{mM}$ ADP and $10 \mathrm{mM} \mathrm{NaF}$ were added. CSPs were calculated according to the following equation

$$
\left.\mathrm{CSP}=\left((\Delta \mathrm{C} / 4)^{\wedge} 2+(\Delta \mathrm{H})^{\wedge} 2\right)\right)^{\wedge} 0.5
$$

( $\Delta \mathrm{C}, \Delta \mathrm{H}$ chemical shift differences in ppm in the ${ }^{13} \mathrm{C}$ and ${ }^{1} \mathrm{H}$ dimensions).

588 Methyl group assignments in the free and RNA bound states of DbpA were published previously (Wurm, 2020; Wurm et al., 2021). Assignments for the RNA bound state could be partially

590 transferred to the closed state (bound to ss-HP92 RNA and ADP/BeF 3 ) based on 3D-NOESY spectra in combination with the structure of the $\mathrm{DbpA} / \mathrm{ss}-\mathrm{HP} 92 / \mathrm{ADP} / \mathrm{BeF}_{3}$ complex. The sample for 
592 the NOESY spectra contained $250 \mu \mathrm{M}$ ILMVA methyl group labeled DbpA, $350 \mu \mathrm{M}$ ss/HP92 RNA, 110 mM NaCl, 25 mM Arg/Glu, 25 mM HEPES, pH 7.3, 1 mM DTT, 5 mM MgCl , 2 mM ADP, 4 mM BeF2 and 15 mM NaF. SOFAST-HMQC based 3D-CCH- and 3D-HCH-NOESY spectra (Rossi et al., 2016) were recorded with a mixing time of $250 \mathrm{~ms}$.

596 Imino proton signals of the substrate duplex of the hp-HP92 RNA in the free state were assigned using a 2D ${ }^{1} \mathrm{H}-{ }^{1} \mathrm{H}$ NOESY spectrum (mixing time $130 \mathrm{~ms}$ ) recorded in SEC buffer at $10{ }^{\circ} \mathrm{C}$ at an

598 RNA concentration of $200 \mu \mathrm{M}$. The assignment of the imino protons of HP92 was published previously (Wurm et al., 2021).

600 NMR spectra were processed with Topspin 4.0.2 or NMRPipe 9.6 (Delaglio et al., 1995) and analyzed using NMRPipe and CARA (Keller, 2004).

\section{PRE measurements}

RNAs for site selective spin labelling contained a 4-thiouridine at the desired labelling position and

604 were chemically synthesized by Dharmacon, see Appendix 1 - table 1 for RNA sequences. RNAs were deprotected according to the protocol provided by Dharmacon. For spin labelling $100 \mu \mathrm{M}$ of 606 the respective RNA was incubated at room temperature in the dark for $24 \mathrm{~h}$ with a 100 -fold excess of 4-(2-Iodoacetamido)-TEMPO in a buffer containing $20 \%$ (v/v) DMSO and 100 mM HEPES, pH

608 8.0. Unreacted 4-(2-Iodoacetamido)-TEMPO was removed by two sodium acetate/EtOH precipitation steps. PRE experiments were performed in NMR buffer lacking DTT using a 1.3 times excess of RNA over DbpA. DbpA concentrations ranged from 40 to $60 \mu \mathrm{M}$. SOFAST-HMQC spectra were recorded before and after reduction of the spin label by addition of $2 \mathrm{mM}$ sodium

612 ascorbate. Peak volumes in both spectra were integrated with NMRPipe and the PRE was calculated as the ratio of the peak volumes before reduction (I) divided by the peak volumes after reduction

$614\left(\mathrm{I}_{0}\right)$. PRE values for the geminal methyl groups of Leu and Val residues were averaged. 


\section{Helicase assays}

616 Fluorescence based single turnover helicase assays were conducted at $25{ }^{\circ} \mathrm{C}$ in 96 -well plates using a TECAN spark platereader. The assay takes advantage of the fluorescence quenching effect of the

618 5' guanosine residues of the 9mer RNA on the 5' fluorescein label. This effect is strongly reduced, when the labeled 9mer is hybridized to the HP92 containing RNA and leads to a reduction of the

620 fluorescence intensity upon unwinding. Rebinding of the 9mer RNA to HP92 containing RNA is prevented by an excess of unlabeled 9mer RNA. See Appendix 1 - table 1 for RNA sequences. 5'

622 fluorescein labeled RNAs were obtained from IDT. Reaction mixtures (100 uL) contained $125 \mathrm{mM}$ NaCl, 25 mM HEPES, pH 7.3, 2 M DbpA, 5 mM MgCl 2 , 25 nM 5’ fluorescein labeled 9mer RNA,

$62437.5 \mathrm{nM}$ HP92 containing RNA, $2 \mu \mathrm{M}$ unlabelled 9mer RNA, $3 \mathrm{mM}$ of the respective nucleotide (ADP, ATP, ADPNP, ADPCP or ATP $\mathrm{AS}$ ). For the $\mathrm{ADP} / \mathrm{BeF}_{3}$ condition $3 \mathrm{mM} \mathrm{BeF}_{2}$ and $10 \mathrm{mM} \mathrm{NaF}$

626 were added in addition to ADP. Initially, 5' fluorescein labeled 9mer RNA (at $1 \mu \mathrm{M}$ ) and HP92 containing RNA (at $1.5 \mu \mathrm{M}$ ) were hybridized in SEC buffer supplemented with $5 \mathrm{mM} \mathrm{MgCl}_{2}$ by

628 heating to $95{ }^{\circ} \mathrm{C}$ and subsequent cooling to room temperature over $\sim 1 \mathrm{~min}$. Then all components except for the nucleotide were mixed and preincubated for 5 min in the platereader. The unwinding reaction was started by addition of nucleotide $\left(+\mathrm{BeF}_{2}\right.$ and $\mathrm{NaF}$ in the case of the $\mathrm{ADP} / \mathrm{BeF}_{3}$ condition) and the fluorescein fluorescence (excitation/emission filter wavelength $485 \mathrm{~nm} / 535 \mathrm{~nm}$ )

632 was recorded every 30 s. Fluorescence time courses were fitted to the following equation

$$
\mathrm{F}=\mathrm{F}_{0}+\Delta \mathrm{F} \cdot \mathrm{e}^{-\mathrm{k} \cdot \mathrm{t}}
$$

634 (F fluorescence intensity, $\mathrm{F}_{0}$ basal fluorescence intensity, $\Delta \mathrm{F}$ fluorescence intensity difference due to unwinding, $\mathrm{k}$ unwinding rate, $\mathrm{t}$ time) using Matlab. All helicase assays were performed in

636 triplicate using the same DbpA preparation, which was stored in small aliquots at -80 C until use. The reported values are mean and standard deviation of the three measurements.

\section{ATPase assays}


The ATPase activity of DbpA in the presence of different RNA constructs was determined using a

coupled pyruvate kinase/lactate dehydrogenase assay (Kiianitsa et al., 2003; Tsu and Uhlenbeck, 1998). The production of ADP is coupled to NADH oxidation, which can be monitored based on

\section{4 pyruvate kinase/lactate dehydrogenase (from rabbit muscle, Sigma Aldrich, \#P0294) and 5 mM} $\mathrm{MgCl}_{2}$ in SEC buffer. Absorption measurements at $340 \mathrm{~nm}$ were conducted in 96-well plates every

$64620 \mathrm{~s}$ using a TECAN spark platereader at $25^{\circ} \mathrm{C}$. ATPase rates were determined based on the following equation after linear fitting of the linear region of the absorption time courses

$$
\mathrm{k}_{\mathrm{obs}}=-\mathrm{dA} / \mathrm{dt}^{*}\left(1 / \mathrm{K}_{\mathrm{path}}\right) *(1 /[\mathrm{DbpA}])
$$

( $\mathrm{k}_{\mathrm{obs}}$ ATPase activity, $\mathrm{dA} / \mathrm{dt}$ slope of the linear fit to the absorption time course, $\mathrm{K}_{\mathrm{path}}$ molar 650 absorption coefficient of $\mathrm{NADH}$ at $340 \mathrm{~nm}$ for the path length in the 96-well plate $\left(2.22 \mathrm{mM}^{-1}\right)$, [DbpA] DbpA concentration). All ATPase assays were performed in triplicate using the same DbpA 652 preparation, which was stored in small aliquots at -80 C until use. The reported values are mean and standard deviation of the three measurements.

\section{Structure modeling}

Structure modeling was performed in torsion angle space using CYANA 3.98 (Güntert et al., 1997).

656 The 1:1 complex between hp-HP92 RNA and DbpA was modeled based on chain B (DbpA), nt 122 of chain F and nt 26-42 of chain G. The torsion angles in these residues were fixed (except for 658 the $\varepsilon$ backbone angle of nt 22 and the $\alpha, \beta, \delta$ and $\zeta$ backbone angles of nt 26) and nt 23-25 of the hpHP92 were modeled to connect chains F and G using the regularize macro implemented in CYANA.

66050 structures were calculated and the structure with the lowest target function was chosen to represent the model. 
662 To model the elongated duplex of the ds-HP92 RNA (Fig. 4) two cytosine residues (corresponding to nt 45 and 46) were added to the 5' end of the ds-HP92 RNA. For these cytosines A-form helix

664 restraints (Richardson et al., 2008) and Watson-Crick hydrogen bond restraints to nt G2/G3 were introduced. All angles of the ds-HP92 RNA except for the $\delta$ and $\varepsilon$ backbone angles of nt 44 were

666 fixed. 50 structures were calculated by simulated annealing and the structure with the lowest target function was chosen to represent the model.

\section{Analytical size exclusion chromatography}

Analytical size exclusion chromatography of RNA and RNA/DbpA complexes was performed at

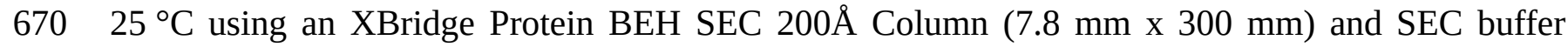
(flowrate $0.5 \mathrm{ml} / \mathrm{min}$ ). RNAs were folded by heating the RNAs at a concentration of $80 \mu \mathrm{M}$ in SEC

672 buffer to $95^{\circ} \mathrm{C}$ for $1 \mathrm{~min}$, followed by rapid cooling on ice. $5 \mathrm{uL}$ of solution containing RNA at a concentration of $40 \mu \mathrm{M}$ in SEC buffer were injected for each run. DbpA was added at a 1.3 fold

674 excess and $2 \mathrm{mM}$ ADP, $2 \mathrm{mM} \mathrm{BeF}_{2}, 2 \mathrm{mM} \mathrm{MgCl}_{2}$ and $10 \mathrm{mM} \mathrm{NaF}$ were added to form the RNA/DbpA/ADP/BeF 3 complexes. The RNA/DbpA/ADP/BeF 3 complex was incubated at least 20

$676 \mathrm{~min}$ at room temperature before analysis. RNA elution was monitored by recording the absorption at $260 \mathrm{~nm}$.

\section{Crystallization and structure determination}

The DbpA/RNA/ADP/BeF3 complexes for crystallization were prepared in SEC buffer using DbpA and RNA concentrations of 200 and $260 \mu \mathrm{M}$, respectively. Before mixing with DbpA RNAs were folded at a concentration of $700 \mu \mathrm{M}$ in $\mathrm{H}_{2} \mathrm{O}$ by heating to $95{ }^{\circ} \mathrm{C}$ for 1 min followed by rapid cooling

682 on ice and subsequent addition of $\mathrm{NaCl}$ to a final concentration of $125 \mathrm{mM}$. Then $3 \mathrm{mM}$ ADP, $5 \mathrm{mM} \mathrm{BeF}_{2}, 5 \mathrm{mM} \mathrm{MgCl}_{2}$ and $16 \mathrm{mM} \mathrm{NaF}$ were added and the complex was incubated at least $1 \mathrm{~h}$

684 at room temperature before crystallization. Crystals were grown using the hanging drop vapor 
diffusion method at $20^{\circ} \mathrm{C}$ after mixing $1 \mathrm{ul}$ of the complex solution with $1 \mathrm{ul}$ of the reservoir

solutions were used:

hp-HP92 RNA: $200 \mathrm{mM} \mathrm{NH}_{4} /$ tartrate, 100 mM Tris, pH 8.0, 20\% (w/v) PEG3350

690

ds-H92 RNA: 0.2 M di-Sodium tartate, 20 \% (w/v) PEG 3350

ss-HP92 RNA: 400 mM KSCN, 100 mM Tris, pH 8.0, 20 \% (w/v) PEG 3350

692 Diffraction data were collected at $-170^{\circ} \mathrm{C}$ and at a wavelength of $0.9766 \AA$ at the EMBL/DESY beamline P13 (Hamburg, Germany) (Cianci et al., 2017) (for the ss/HP92 RNA/DbpA complex) or

694 at a wavelength of $1.000 \AA$ at the SLS beamline X06SA (Villigen, Switzerland) (Mueller et al., 2012) (for the hp/HP92 and ds/HP92 RNA/DbpA complexes). The collected data was integrated,

696 merged and scaled using XDS (Kabsch, 2010). Phasing of the hp-HP92 RNA complex was performed by molecular replacement using PHASER (McCoy et al., 2007) and the structures of the

698 DEAD-box helicase VASA (PDB 2DB3) (Sengoku et al., 2006) and of the RRM of the DbpA homolog YxiN (PDB 3MOJ) (Hardin et al., 2010) as search models. For the other two complexes

700 the DbpA structure of the hp-HP92 RNA complex was used as a molecular replacement search model. The structures were refined by iterative rounds of manual model building in COOT (Emsley

702 and Cowtan, 2004) and refinement using Phenix.refine (Afonine et al., 2012). Data collection and refinement statistics are summarized in Figure 3 - figure supplement 1 . Structure representations 704 were generated with UCSF ChimeraX (Pettersen et al., 2021).

\section{Data availability}


706 Structure factors and atomic coordinates have been deposited in the PDB with accession codes 7PLI (ss-HP92/DbpA complex), 7PMQ (hp-HP92/DbpA complex) and 7PMM (ds-H92/DbpA complex).

\section{Acknowledgment}

I am indebted to Remco Sprangers for his generous support, fruitful discussion, lab space and

710 spectrometer time. I would like to thank Jens Wöhnert and Konstantin Neißner for acquisition of the diffraction data of the ss-HP92 RNA/DbpA complex and Olga Rudi for help with protein

712 preparation. The Paul Scherrer Institut, Villigen, Switzerland and the EMBL Hamburg are acknowledged for synchrotron radiation beamtime at beamline P13 at the PETRA III storage ring

714 and at beamline PXI of the SLS. I am grateful to Christoph Engel and Ursula Neu for helpful discussions regarding structure refinement and I would like to thank Johanna Stöfl for lab support

716 and Jan Overbeck and Jobst Liebau for critical reading of the manuscript. The Deutsche Forschungs Gemeinschaft is acknowledged for funding (DFG grant no. WU 988/1-1).

\section{Competing interests}

No competing interests declared.

\section{References}

Afonine PV, Grosse-Kunstleve RW, Echols N, Headd JJ, Moriarty NW, Mustyakimov M, Terwilliger TC, Urzhumtsev A, Zwart PH, Adams PD. 2012. Towards automated crystallographic structure refinement with phenix.refine. Acta Crystallogr D Biol Crystallogr 68:352-367. doi:10.1107/S0907444912001308

Andreou AZ, Harms U, Klostermeier D. 2019. Single-stranded regions modulate conformational dynamics and ATPase activity of eIF4A to optimize 5'-UTR unwinding. Nucleic Acids Res 47:5260-5275. doi:10.1093/nar/gkz254 
bioRxiv preprint doi: https://doi.org/10.1101/2022.02.23.481582; this version posted February 23, 2022. The copyright holder for this preprint (which was not certified by peer review) is the author/funder, who has granted bioRxiv a license to display the preprint in perpetuity. It is made available under aCC-BY 4.0 International license.

Ballut L, Marchadier B, Baguet A, Tomasetto C, Séraphin B, Le Hir H. 2005. The exon junction core complex is locked onto RNA by inhibition of eIF4AIII ATPase activity. Nat Struct Mol Biol 12:861-869. doi:10.1038/nsmb990

Bowers HA, Maroney PA, Fairman ME, Kastner B, Lührmann R, Nilsen TW, Jankowsky E. 2006. Discriminatory RNP remodeling by the DEAD-box protein DED1. RNA 12:903-912. doi:10.1261/rna.2323406

Chen Z, Li Z, Hu X, Xie F, Kuang S, Zhan B, Gao W, Chen X, Gao S, Li Y, Wang Y, Qian F, Ding C, Gan J, Ji C, Xu X-W, Zhou Z, Huang J, He HH, Li J. 2020. Structural Basis of Human Helicase DDX21 in RNA Binding, Unwinding, and Antiviral Signal Activation. Adv Sci (Weinh) 7:2000532. doi:10.1002/advs.202000532

Cianci M, Bourenkov G, Pompidor G, Karpics I, Kallio J, Bento I, Roessle M, Cipriani F, Fiedler S, Schneider TR. 2017. P13, the EMBL macromolecular crystallography beamline at the lowemittance PETRA III ring for high- and low-energy phasing with variable beam focusing. $J$ Synchrotron Radiat 24:323-332. doi:10.1107/S1600577516016465

Clore GM, Tang C, Iwahara J. 2007. Elucidating transient macromolecular interactions using paramagnetic relaxation enhancement. Curr Opin Struct Biol 17:603-616. doi:10.1016/j.sbi.2007.08.013

Collins R, Karlberg T, Lehtiö L, Schütz P, van den Berg S, Dahlgren L-G, Hammarström M, Weigelt J, Schüler H. 2009. The DEXD/H-box RNA helicase DDX19 is regulated by an \{alpha\}-helical switch. J Biol Chem 284:10296-10300. doi:10.1074/jbc.C900018200

Del Campo M, Lambowitz AM. 2009. Structure of the Yeast DEAD box protein Mss116p reveals two wedges that crimp RNA. Mol Cell 35:598-609. doi:10.1016/j.molcel.2009.07.032

Delaglio F, Grzesiek S, Vuister GeertenW, Zhu G, Pfeifer J, Bax A. 1995. NMRPipe: A multidimensional spectral processing system based on UNIX pipes. Journal of Biomolecular NMR 6. doi:10.1007/BF00197809

Diges CM, Uhlenbeck OC. 2001. Escherichia coli DbpA is an RNA helicase that requires hairpin 92 of 23S rRNA. EMBO J 20:5503-5512. doi:10.1093/emboj/20.19.5503

Emsley P, Cowtan K. 2004. Coot: model-building tools for molecular graphics. Acta Crystallogr D Biol Crystallogr 60:2126-2132. doi:10.1107/S0907444904019158

Fairman-Williams ME, Guenther U-P, Jankowsky E. 2010. SF1 and SF2 helicases: family matters. Curr Opin Struct Biol 20:313-324. doi:10.1016/j.sbi.2010.03.011

Guillerez J, Lopez PJ, Proux F, Launay H, Dreyfus M. 2005. A mutation in T7 RNA polymerase that facilitates promoter clearance. Proc Natl Acad Sci USA 102:5958-5963. doi:10.1073/pnas.0407141102

Güntert P, Mumenthaler C, Wüthrich K. 1997. Torsion angle dynamics for NMR structure calculation with the new program DYANA. J Mol Biol 273:283-298. doi:10.1006/jmbi.1997.1284

Hardin JW, Hu YX, McKay DB. 2010. Structure of the RNA binding domain of a DEAD-box helicase bound to its ribosomal RNA target reveals a novel mode of recognition by an RNA recognition motif. J Mol Biol 402:412-427. doi:10.1016/j.jmb.2010.07.040

Henn A, Cao W, Licciardello N, Heitkamp SE, Hackney DD, De La Cruz EM. 2010. Pathway of ATP utilization and duplex rRNA unwinding by the DEAD-box helicase, DbpA. Proc Natl Acad Sci USA 107:4046-4050. doi:10.1073/pnas.0913081107 
Jarmoskaite I, Russell R. 2014. RNA helicase proteins as chaperones and remodelers. Annu Rev Biochem 83:697-725. doi:10.1146/annurev-biochem-060713-035546

Kabsch W. 2010. Integration, scaling, space-group assignment and post-refinement. Acta Crystallogr D Biol Crystallogr 66:133-144. doi:10.1107/S0907444909047374

Keller R. 2004. The computer aided resonance assignment tutorial. Goldau: Cantina Verl.

Kiianitsa K, Solinger JA, Heyer W-D. 2003. NADH-coupled microplate photometric assay for kinetic studies of ATP-hydrolyzing enzymes with low and high specific activities. Anal Biochem 321:266-271. doi:10.1016/s0003-2697(03)00461-5

Linder P, Jankowsky E. 2011. From unwinding to clamping - the DEAD box RNA helicase family. Nat Rev Mol Cell Biol 12:505-516. doi:10.1038/nrm3154

Liu F, Putnam A, Jankowsky E. 2008. ATP hydrolysis is required for DEAD-box protein recycling but not for duplex unwinding. Proc Natl Acad Sci U S A 105:20209-20214. doi:10.1073/pnas.0811115106

Mallam AL, Del Campo M, Gilman B, Sidote DJ, Lambowitz AM. 2012. Structural basis for RNAduplex recognition and unwinding by the DEAD-box helicase Mss116p. Nature 490:121125. doi:10.1038/nature11402

McCoy AJ, Grosse-Kunstleve RW, Adams PD, Winn MD, Storoni LC, Read RJ. 2007. Phaser crystallographic software. J Appl Crystallogr 40:658-674. doi:10.1107/S0021889807021206

Montpetit B, Thomsen ND, Helmke KJ, Seeliger MA, Berger JM, Weis K. 2011. A conserved mechanism of DEAD-box ATPase activation by nucleoporins and InsP6 in mRNA export. Nature 472:238-242. doi:10.1038/nature09862

Mueller M, Wang M, Schulze-Briese C. 2012. Optimal fine $\phi$-slicing for single-photon-counting pixel detectors. Acta Crystallogr D Biol Crystallogr 68:42-56. doi:10.1107/S0907444911049833

Ngo TD, Partin AC, Nam Y. 2019. RNA Specificity and Autoregulation of DDX17, a Modulator of MicroRNA Biogenesis. Cell Rep 29:4024-4035.e5. doi:10.1016/j.celrep.2019.11.059

Pettersen EF, Goddard TD, Huang CC, Meng EC, Couch GS, Croll TI, Morris JH, Ferrin TE. 2021. UCSF ChimeraX: Structure visualization for researchers, educators, and developers. Protein Sci 30:70-82. doi:10.1002/pro.3943

Putnam AA, Jankowsky E. 2013. DEAD-box helicases as integrators of RNA, nucleotide and protein binding. Biochim Biophys Acta 1829:884-893. doi:10.1016/j.bbagrm.2013.02.002

Raj S, Bagchi D, Orero JV, Banroques J, Tanner NK, Croquette V. 2019. Mechanistic characterization of the DEAD-box RNA helicase Ded1 from yeast as revealed by a novel technique using single-molecule magnetic tweezers. Nucleic Acids Res 47:3699-3710. doi:10.1093/nar/gkz057

Ren Y, Schmiege P, Blobel G. 2017. Structural and biochemical analyses of the DEAD-box ATPase Sub2 in association with THO or Yra1. Elife 6:e20070. doi:10.7554/eLife.20070

Richardson JS, Schneider B, Murray LW, Kapral GJ, Immormino RM, Headd JJ, Richardson DC, Ham D, Hershkovits E, Williams LD, Keating KS, Pyle AM, Micallef D, Westbrook J, Berman HM, RNA Ontology Consortium. 2008. RNA backbone: consensus all-angle conformers and modular string nomenclature (an RNA Ontology Consortium contribution). RNA 14:465-481. doi:10.1261/rna.657708 
Rogers GW, Richter NJ, Merrick WC. 1999. Biochemical and Kinetic Characterization of the RNA Helicase Activity of Eukaryotic Initiation Factor 4A. Journal of Biological Chemistry 274:12236-12244. doi:10.1074/jbc.274.18.12236

Rossi P, Xia Y, Khanra N, Veglia G, Kalodimos CG. 2016. 15N and 13C- SOFAST-HMQC editing enhances 3D-NOESY sensitivity in highly deuterated, selectively [1H,13C]-labeled proteins. J Biomol NMR 66:259-271. doi:10.1007/s10858-016-0074-5

Russell R, Jarmoskaite I, Lambowitz AM. 2013. Toward a molecular understanding of RNA remodeling by DEAD-box proteins. RNA Biol 10:44-55. doi:10.4161/rna.22210

Samatanga B, Klostermeier D. 2014. DEAD-box RNA helicase domains exhibit a continuum between complete functional independence and high thermodynamic coupling in nucleotide and RNA duplex recognition. Nucleic Acids Res 42:10644-10654. doi:10.1093/nar/gku747

Schanda P, Kupce E, Brutscher B. 2005. SOFAST-HMQC experiments for recording twodimensional heteronuclear correlation spectra of proteins within a few seconds. J Biomol NMR 33:199-211. doi:10.1007/s10858-005-4425-X

Sengoku T, Nureki O, Nakamura A, Kobayashi S, Yokoyama S. 2006. Structural Basis for RNA Unwinding by the DEAD-Box Protein Drosophila Vasa. Cell 125:287-300. doi:10.1016/j.cell.2006.01.054

Sharpe Elles LM, Sykes MT, Williamson JR, Uhlenbeck OC. 2009. A dominant negative mutant of the E. coli RNA helicase DbpA blocks assembly of the 50S ribosomal subunit. Nucleic Acids Res 37:6503-6514. doi:10.1093/nar/gkp711

Snoussi K, Leroy JL. 2001. Imino proton exchange and base-pair kinetics in RNA duplexes. Biochemistry 40:8898-8904. doi:10.1021/bi010385d

Sun Y, Atas E, Lindqvist LM, Sonenberg N, Pelletier J, Meller A. 2014. Single-molecule kinetics of the eukaryotic initiation factor 4AI upon RNA unwinding. Structure 22:941-948. doi:10.1016/j.str.2014.04.014

Theissen B, Karow AR, Köhler J, Gubaev A, Klostermeier D. 2008. Cooperative binding of ATP and RNA induces a closed conformation in a DEAD box RNA helicase. Proc Natl Acad Sci USA 105:548-553. doi:10.1073/pnas.0705488105

Tran EJ, Zhou Y, Corbett AH, Wente SR. 2007. The DEAD-box protein Dbp5 controls mRNA export by triggering specific RNA:protein remodeling events. Mol Cell 28:850-859. doi:10.1016/j.molcel.2007.09.019

Tsu CA, Uhlenbeck OC. 1998. Kinetic analysis of the RNA-dependent adenosinetriphosphatase activity of DbpA, an Escherichia coli DEAD protein specific for 23S ribosomal RNA. Biochemistry 37:16989-16996. doi:10.1021/bi981837y

Wang S, Hu Y, Overgaard MT, Karginov FV, Uhlenbeck OC, McKay DB. 2006. The domain of the Bacillus subtilis DEAD-box helicase YxiN that is responsible for specific binding of 23S rRNA has an RNA recognition motif fold. RNA 12:959-967. doi:10.1261/rna.5906

Wong EV, Cao W, Vörös J, Merchant M, Modis Y, Hackney DD, Montpetit B, De La Cruz EM. 2016. P(I) Release Limits the Intrinsic and RNA-Stimulated ATPase Cycles of DEAD-Box Protein 5 (Dbp5). J Mol Biol 428:492-508. doi:10.1016/j.jmb.2015.12.018

Wurm JP. 2020. Assignment of the Ile, Leu, Val, Met and Ala methyl group resonances of the DEAD-box RNA helicase DbpA from E. coli. Biomol NMR Assign 15:121-128. doi:10.1007/s12104-020-09994-z 
Wurm JP, Glowacz K-A, Sprangers R. 2021. Structural basis for the activation of the DEAD-box RNA helicase DbpA by the nascent ribosome. Proc Natl Acad Sci U S A 118:e2105961118. doi:10.1073/pnas.2105961118

Xiol J, Spinelli P, Laussmann MA, Homolka D, Yang Z, Cora E, Couté Y, Conn S, Kadlec J, Sachidanandam R, Kaksonen M, Cusack S, Ephrussi A, Pillai RS. 2014. RNA clamping by Vasa assembles a piRNA amplifier complex on transposon transcripts. Cell 157:1698-1711. doi:10.1016/j.cell.2014.05.018

Yang Q, Del Campo M, Lambowitz AM, Jankowsky E. 2007. DEAD-box proteins unwind duplexes by local strand separation. Mol Cell 28:253-263. doi:10.1016/j.molcel.2007.08.016 


\section{Supplementary Material}

a

H. sapiens DDX21, Chen et al.

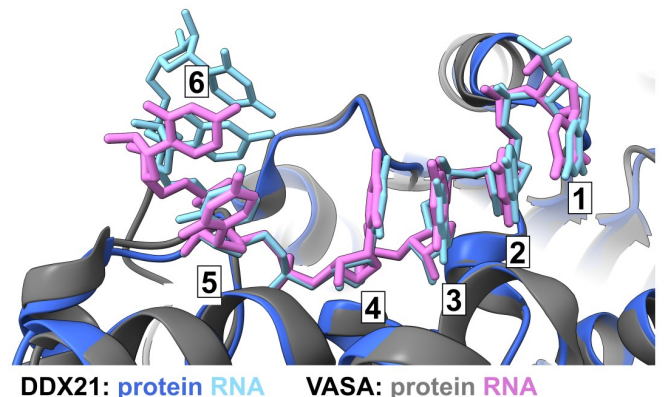

C S. cerevisae Mss116, Del Campo et al.

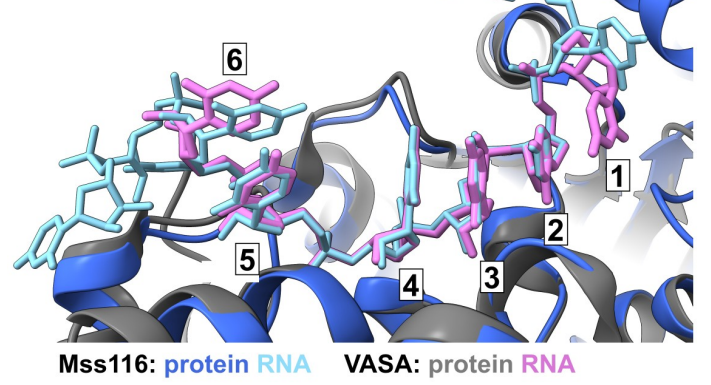

e H. sapiens DDX17, Ngo et al.

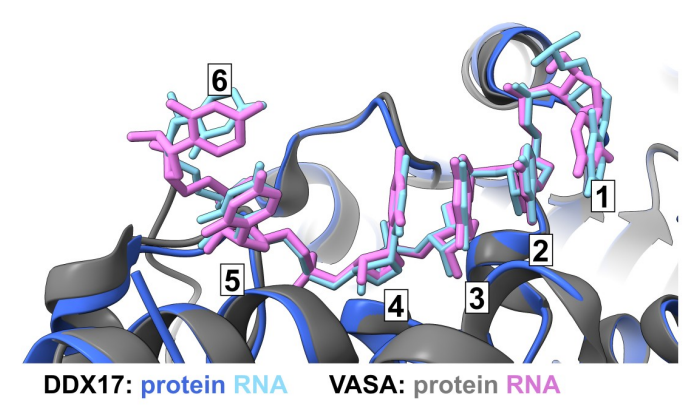

g S.cerevisiae Dbp5, Wong et al.

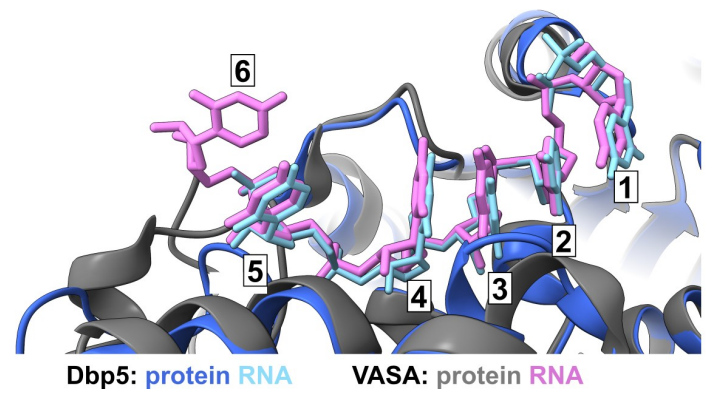

b H. sapiens DDX19, Collins et al.

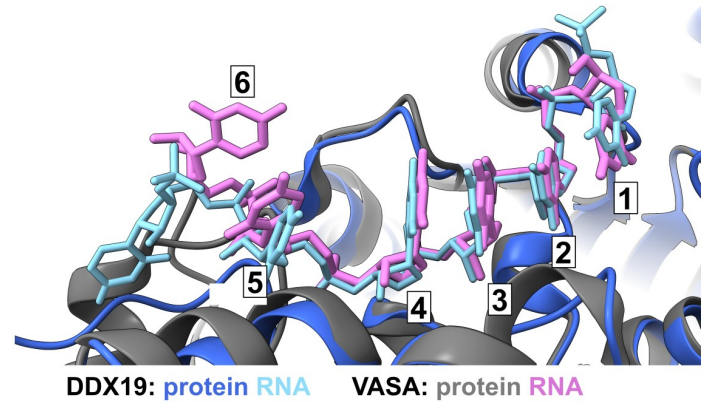

d S. cerevisae Dbp5, Montpetit et al.

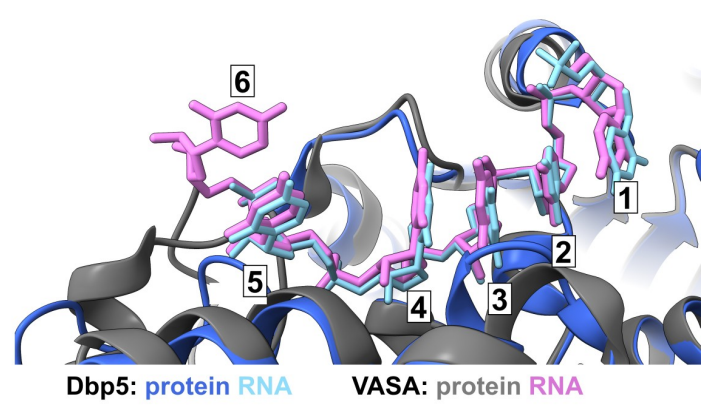

$\mathbf{f}$

S. cerevisae Sub2, Ren et al.

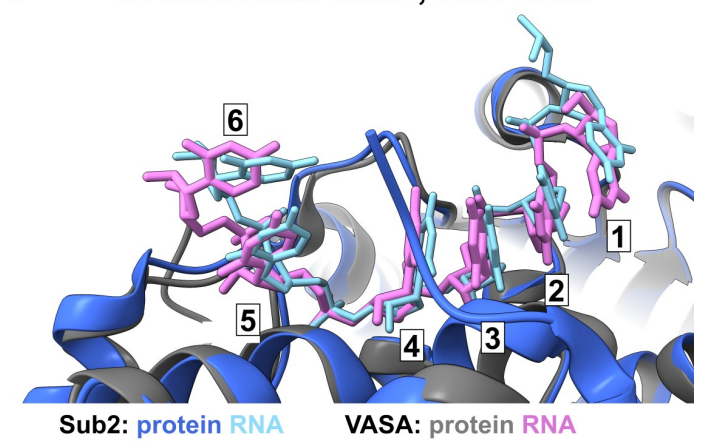

722 Figure 1 - figure supplement 1: Published structures of ssRNA product-bound DEAD-box helicases in the closed-conformation reveal a highly conserved binding mode. 
724 Close-up of the active site of the helicase core bound to ssRNA. Shown are comparisons between the structure of the DEAD-box helicase VASA from $D$. melanogaster with the structures of (a) $H$.

726 sapiens DDX21 (Chen et al., 2020), (b) H. sapiens DDX19 (Collins et al., 2009), (c) S. cerevisiae Mss116 (Del Campo and Lambowitz, 2009), (d) S. cerevisiae Dbp5 (Montpetit et al., 2011), (e) H.

728 sapiens DDX17 (Ngo et al., 2019), (f) S. cerevisiae Sub2 (Ren et al., 2017) and S. cerevisiae Dbp5 (Wong et al., 2016). The VASA helicase and the bound ssRNA are shown in grey and pink. The

730 other helicases and bound ssRNAs are colored dark and light blue. The nucleotides that interact with the active site are numbered 1-6. Basically identical conformations are observed for nt 1-5 and

732 the phosphate group of nt 6, whereas the conformation of the ribose and base of nt 6 are less well conserved. 

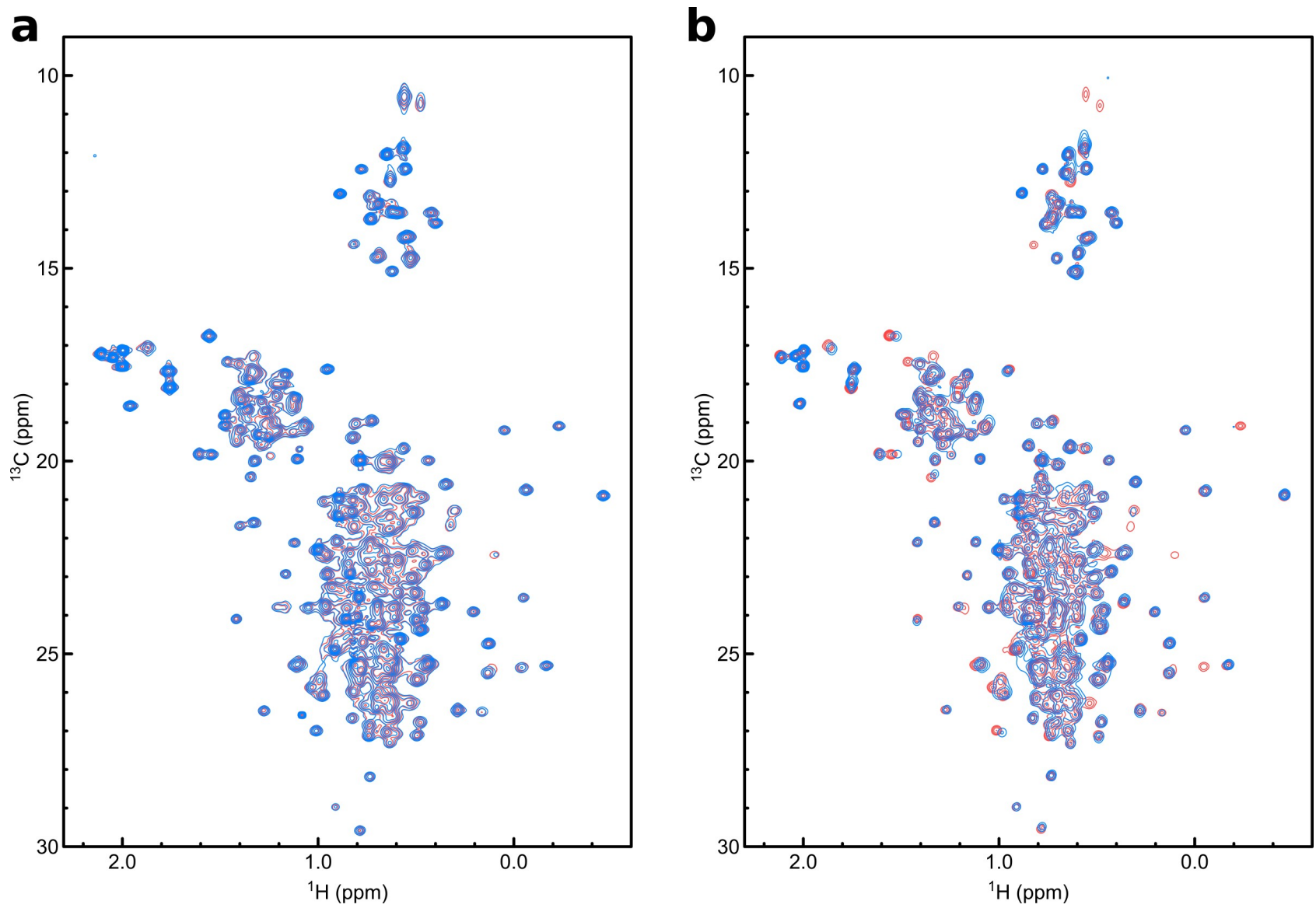

734 Figure 2 - figure supplement 1: ATPYS is rapidly hydrolyzed by DbpA in the presence of ssHP92 RNA.

736 (a) Overlay of ${ }^{1} \mathrm{H}^{13} \mathrm{C}$-HMQC spectra of ILMVA-methyl group labeled DbpA in complex with ssHP92 RNA after addition of ADP (red) or ATPyS (blue). The spectra are virtually identical indicating that the $\mathrm{ATP} \gamma \mathrm{S}$ has been hydrolyzed to ADP before the start of the measurement. (b) Overlay of ${ }^{1} \mathrm{H}^{13} \mathrm{C}$-HMQC spectra of ILMVA-methyl group labeled DbpA after addition of ADP

740 (red) or ATPYS (blue). In the absence of ss-HP92 the spectra are clearly different indicating that ATP $\gamma \mathrm{S}$ is only hydrolyzed in the presence of ss-HP92 and that binding of ADP and ATP $\gamma \mathrm{S}$ can be discriminated based on ${ }^{1} \mathrm{H}^{13} \mathrm{C}-\mathrm{HMQC}$ spectra of DbpA. 


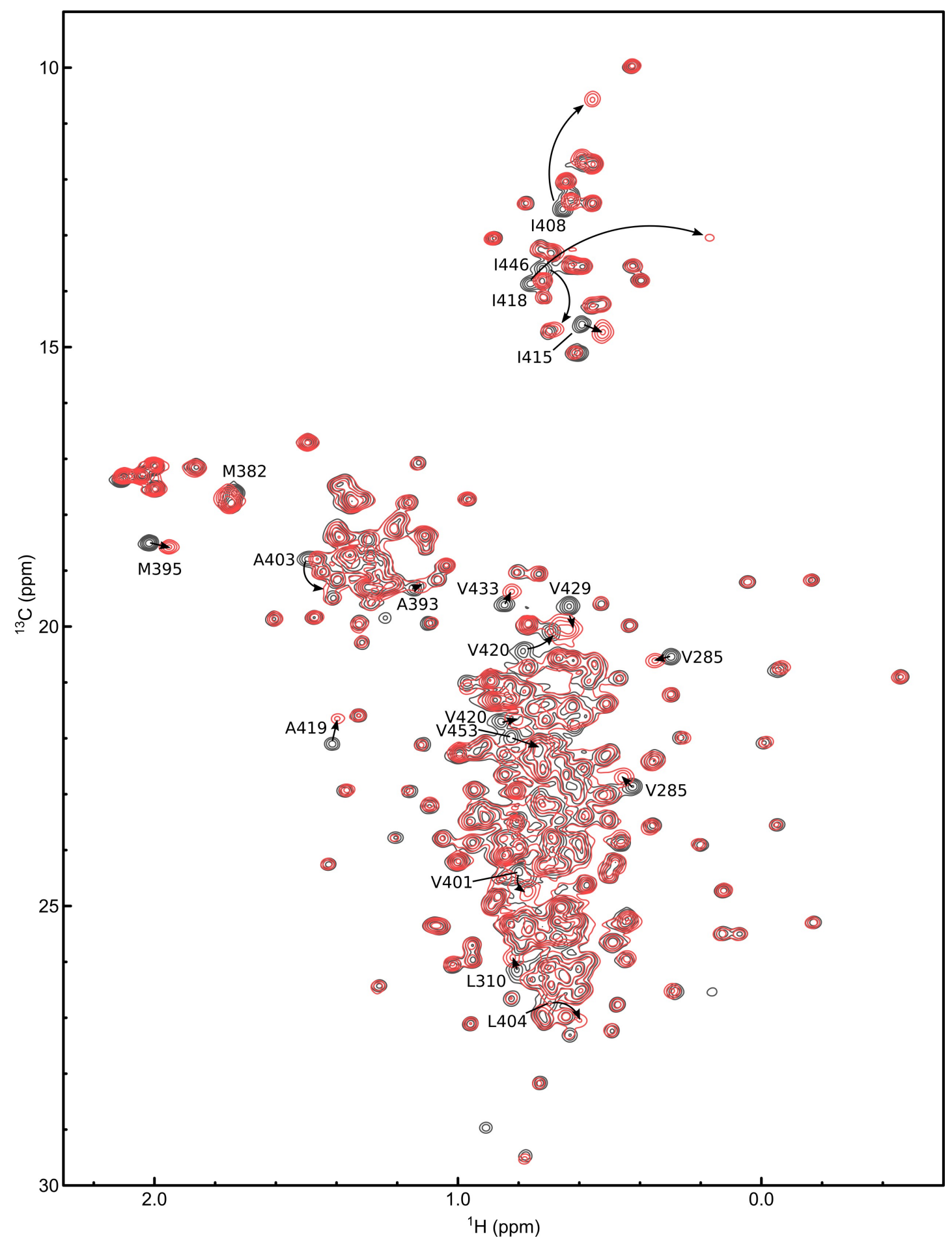

Figure 2 - figure supplement 2: Binding of hp-HP92 to DbpA followed by methyl NMR.

744 Overlay of ${ }^{1} \mathrm{H}^{13} \mathrm{C}$-HMQC spectra of ILMVA-methyl group labeled DbpA in the apo state (black) and after addition of a 1.3-fold excess of hp-HP92 RNA (red). Assignments are given for methyl group signals that show large CSPs and the peak position in the complex is indicated by an arrow. Note that all signals that show large CSPs belong to the RRM (res. 380-457) or are located in the proximity of the RRM (V285/L310). See figure 2 of the main text for quantification of the CSPs. 


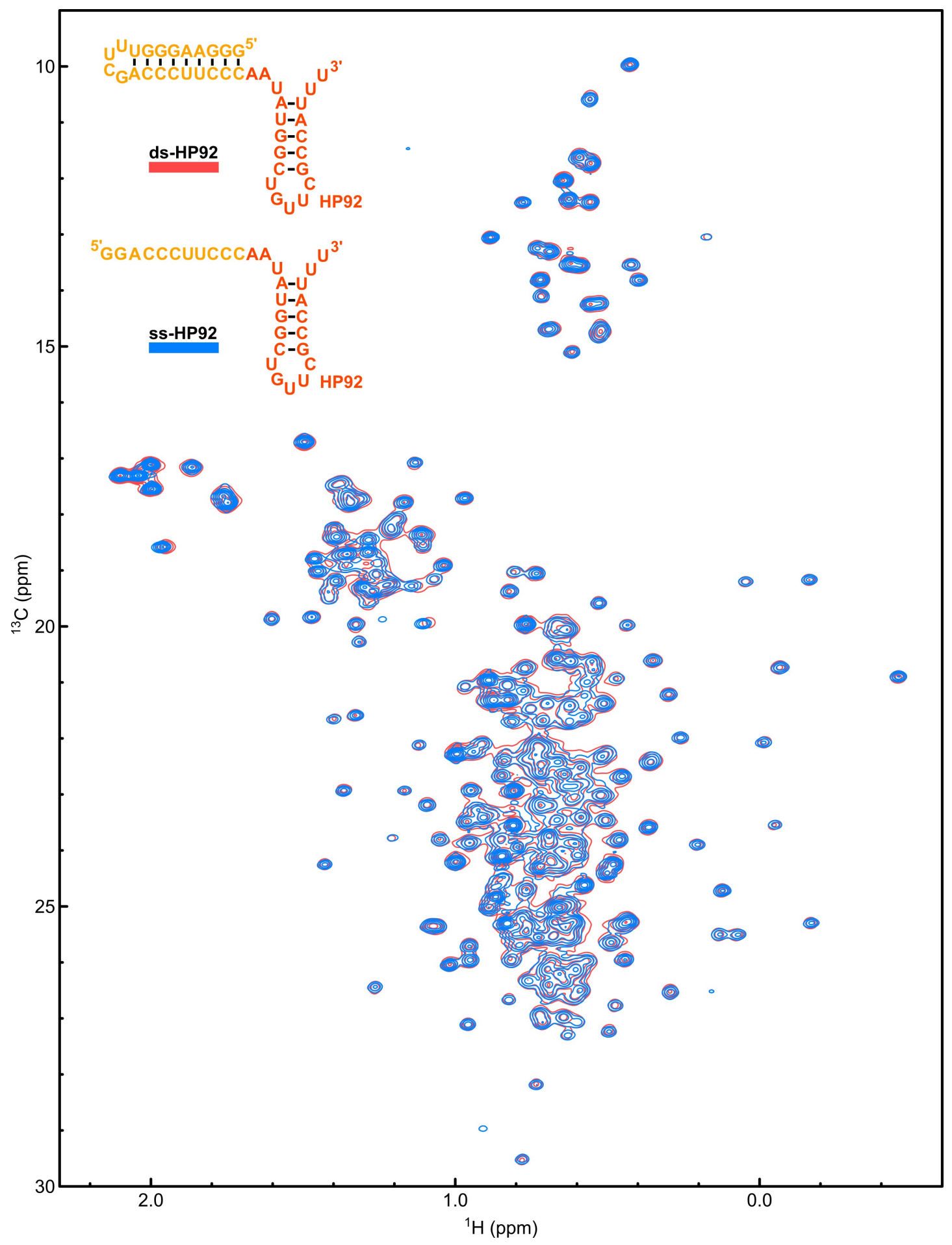

Figure 2 - figure supplement 3: Spectra of DbpA in complex with ss-HP92 and hp-HP92 RNAs are virtually identical.

Overlay of ${ }^{1} \mathrm{H}^{13} \mathrm{C}$-HMQC spectra of ILMVA-methyl group labeled DbpA in complex with the hp752 HP92 (red) or the ss-HP92 RNA (blue). The spectra are virtually identical (see also Fig. 2 of the main text). The RNA constructs are shown in the top left. 


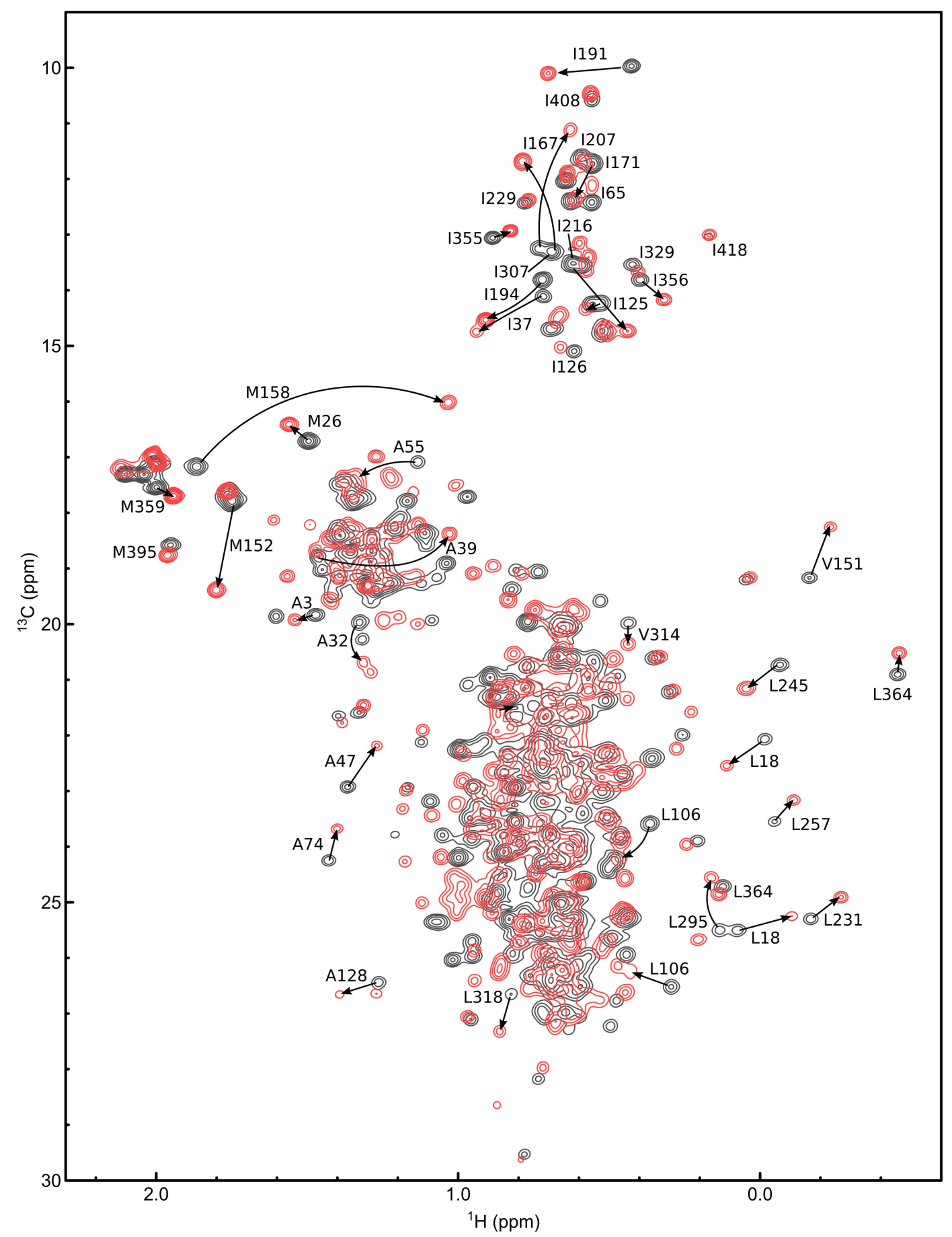

754 Figure 2 - figure supplement 4: Binding of $\mathrm{ADP}_{\mathbf{B e F}}$ to the hp-HP92/DbpA complex followed by methyl NMR.

756 Overlay of ${ }^{1} \mathrm{H}^{13} \mathrm{C}$-HMQC spectra of ILMVA-methyl group labeled DbpA in complex with hp-HP92 RNA (black) and after addition of a $\mathrm{ADP} / \mathrm{BeF}_{3}$ (red). Assignments are given for methyl group

758 signals that show large CSPs and the new peak position is indicated by an arrow. Note that signals from both RecA domains show large CSPs. See Fig. 2 of the main text for quantification of the CSPs. As shown previously (Wurm et al., 2021) these CSPs signify the formation of the closed state of the helicase core. 


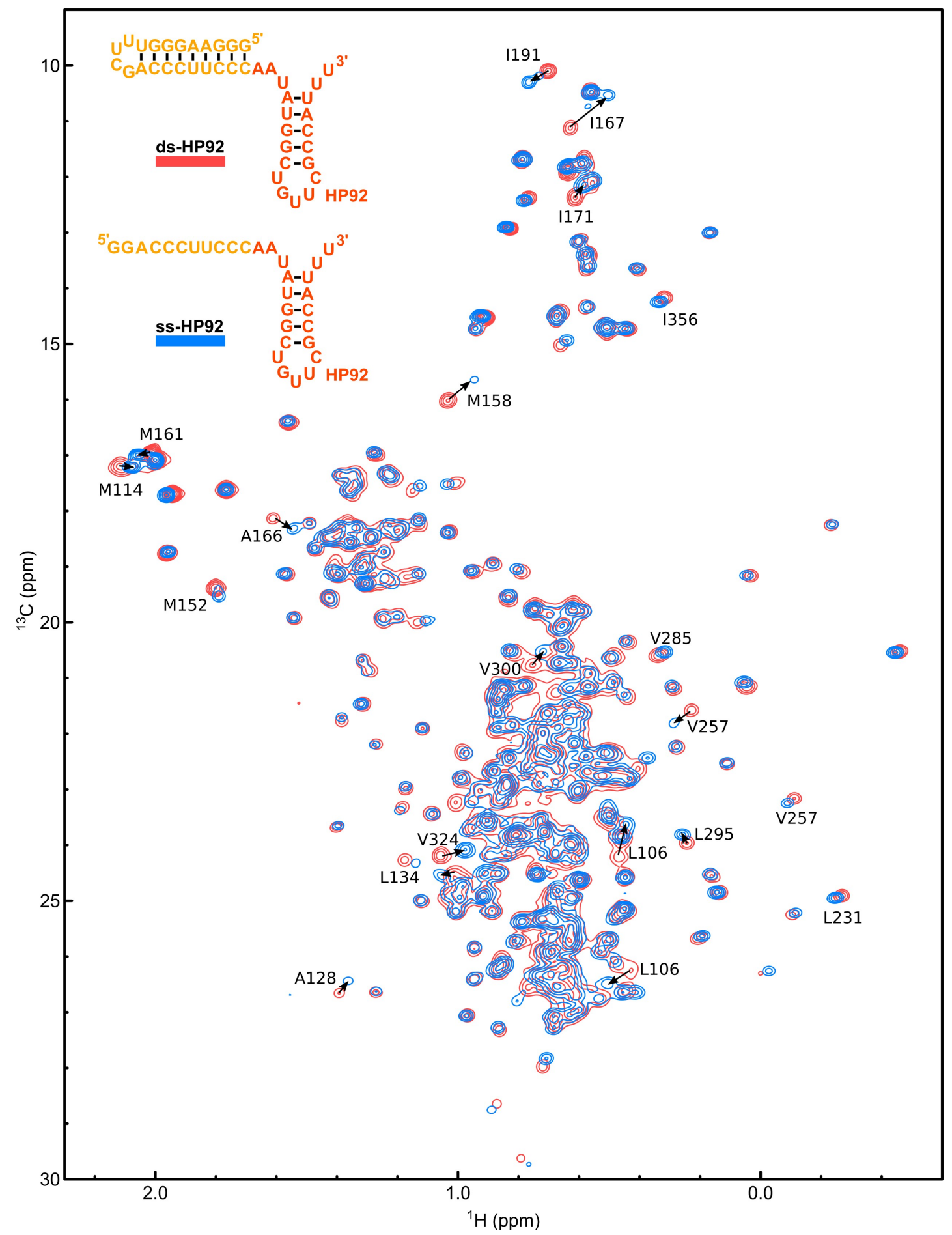

762 Figure 2 - figure supplement 5: Spectra of $\mathrm{DbpA} / \mathrm{ADP} / \mathrm{BeF}_{3}$ in complex with and ss-HP92 and hp-HP92 complex are similar, but display marked differences.

764 Overlay of ${ }^{1} \mathrm{H}^{13} \mathrm{C}$-HMQC spectra of ILMVA-methyl group labeled DbpA in complex with $\mathrm{ADP} / \mathrm{BeF}_{3}$ and the hp-HP92 RNA (red) or in complex with $\mathrm{ADP} / \mathrm{BeF}_{3}$ and the ss-HP92 RNA (blue). Assignments are shown for signals with pronounced differences between the two constructs. The differences cluster in the vicinity of the RNA binding site of the RecA domains. See Fig. 2 of the main text for a quantitative comparison. The RNA constructs are shown in the top left. 
bioRxiv preprint doi: https://doi org/10.1101/2022.02.23.481582; this version posted February 23,2022 . The copyright holder for this preprint (which was not certified by peer review) is the author/funder, who has granted bioRxiv a license to display the preprint in perpetuity. It is made available under aCC-BY 4.0 International license.

Figure 3 - figure supplement 1: Crystallographic data and refinement

\begin{tabular}{|c|c|c|c|}
\hline RNA construct & ss-HP92 (7PLI) & ds-HP92 (7PMM) & hp-HP92 (7PMQ) \\
\hline Space group & P1 & $P 4_{2} 2_{1} 2$ & $\mathrm{P} 4_{3} 2_{1} 2$ \\
\hline Cell dimensions (a, b, c ( $(\AA))$ & $\begin{array}{llll}58.643 & 121.599 & 122.417\end{array}$ & 169.69169 .69111 .99 & 159.644159 .644204 .682 \\
\hline$\alpha, \beta, y\left(^{\circ}\right)$ & 97.1692 .43103 .44 & 90.0090 .0090 .00 & 90.0090 .0090 .00 \\
\hline Resolution $(\AA)$ & 2.50 & 3.00 & 3.22 \\
\hline $\mathrm{R}$ merge & $0.113(0.640)$ & 0.1214 (1.043) & $0.246(1.793)$ \\
\hline $\mathrm{I} / \sigma(\mathrm{l})$ & $7.25(1.75)$ & 24.40 (3.05) & $10.72(1.42)$ \\
\hline CC $1 / 2$ & $0.990(0.75)$ & $0.998(0.914)$ & $0.998(0.553)$ \\
\hline Completeness (\%) & $96.62(96.52)$ & $99.93(99.97)$ & $99.72(99.65)$ \\
\hline Redundancy & $3.6(3.6)$ & $36.2(15.2)$ & $13.6(14.0)$ \\
\hline \multicolumn{4}{|l|}{ Refinement } \\
\hline Resolution $(\AA)$ & $56.9-2.50(2.59-2.50)$ & $48.39-3.0(3.11-3.0)$ & $49.33-3.22(3.33-3.22)$ \\
\hline Unique reflections & 108844 (10869) & 33295 (3268) & 43424 (4266) \\
\hline$R$ work / $R$ free & $0.2133 / 0.2469$ & $0.1971 / 0.2246$ & $0.2276 / 0.2637$ \\
\hline No. atoms & 23591 & 8687 & 17493 \\
\hline Protein & 23321 & 8601 & 17345 \\
\hline ligands & 246 & 78 & 146 \\
\hline Water & 24 & 8 & 0 \\
\hline B factors & 69.07 & 116.82 & 86.14 \\
\hline Protein & 69.18 & 116.99 & 86.22 \\
\hline ligands & 61.63 & 101.51 & 76.47 \\
\hline Water & 46.95 & 82.26 & - \\
\hline \multicolumn{4}{|l|}{ R.m.s. deviations } \\
\hline Bond lengths $(\AA)$ & 0.003 & 0.005 & 0.004 \\
\hline Bond angles $\left({ }^{\circ}\right)$ & 0.83 & 0.85 & 0.71 \\
\hline \multicolumn{4}{|l|}{ Ramachandran statistics } \\
\hline Favored regions (\%) & 98.37 & 97.63 & 95.66 \\
\hline Allowed regions (\%) & 1.55 & 2.26 & 4.01 \\
\hline Outliers (\%) & 0.07 & 0.11 & 0.33 \\
\hline
\end{tabular}

770 The highest resolution shell values are indicated in parenthesis. 
a

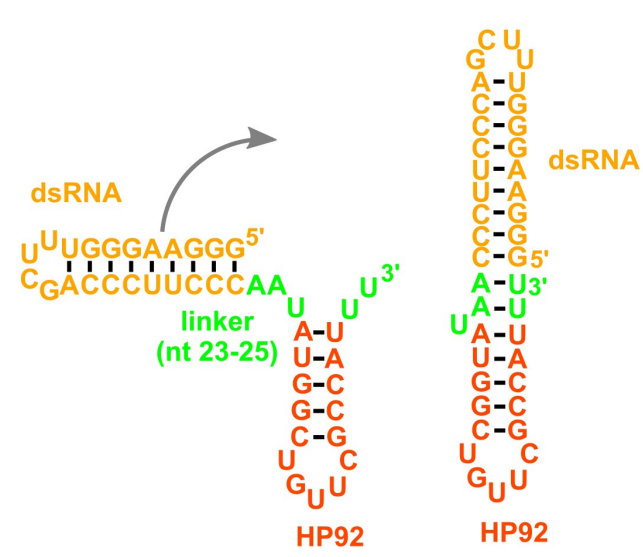

b

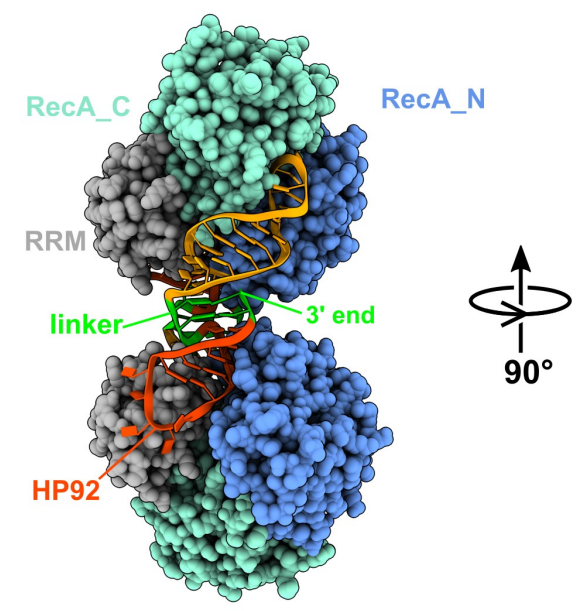

2:2 complex

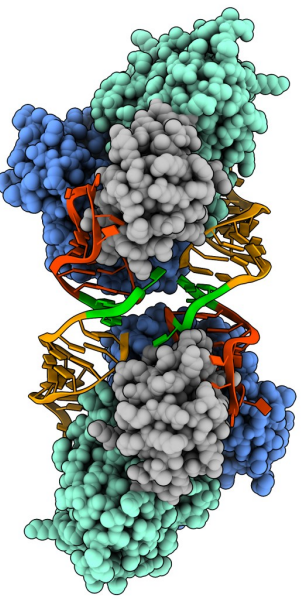

e

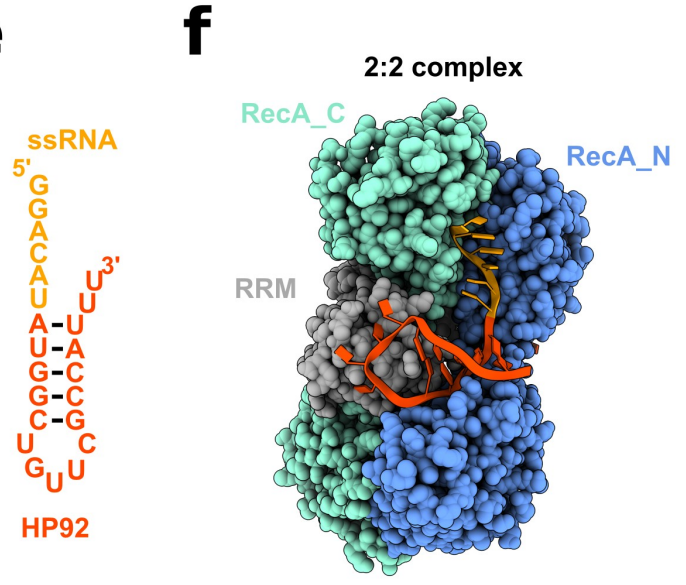

Figure 3 - figure supplement 2: Crystallized RNA constructs and 2:2 complexes

772 (a) RNA construct used for crystallization of the hp-HP92/DbpA/ADP/BeF 3 complex. The expected secondary structure of the hp-HP92 RNA is shown on the left and the secondary structure observed 774 in the crystal is shown on the right. The linker (nt 23-25 green) between the substrate hairpin (orange) and HP92 (red) forms two base pairs with the uridines at the 3' end, which leads to co coaxial stacking of the two helices. (b) Crystallized 2:2 complex between 2 DbpA molecules and 2 hp-HP92 RNAs (chains A/B/FG). Each RNA interacts with two DpbA molecules: HP92 binds to

778 the RRM of one DbpA molecule and the substrate hairpin interacts with the RecA domains of the other DbpA molecule. (c) ds-HP92 RNA construct used for crystallization of the ds-HP92/DbpA/ADP/BeF 3 complex. To facilitate crystallization the construct was designed to mimic the conformation of the hp-HP92 RNA observed in the crystal (compare to (a)). Instead of the hairpin the ds-HP92 RNA possess a ss/dsRNA junction with 5' ssRNA overhang of 3 nt that 
bioRxiv preprint doi: https://doi.org/10.1101/2022.02.23.481582; this version posted February 23, 2022. The copyright holder for this preprint (which was not certified by peer review) is the author/funder, who has granted bioRxiv a license to display the preprint in perpetuity. It is made available under aCC-BY 4.0 International license.

interacts with the RecA domains of the helicase core. (d) Crystallized 2:2 complex between 2 DbpA 784 molecules and two ds-HP92 RNAs (chains A/B/C/D). (e) ss-HP92 RNA construct used for crystallization of the ss-HP92/DbpA/ADP/BeF 3 complex. (f) Crystallized 2:2 complex between two

786 DbpA molecules and two ss-HP92 RNAs (chains A/B/C/D) 


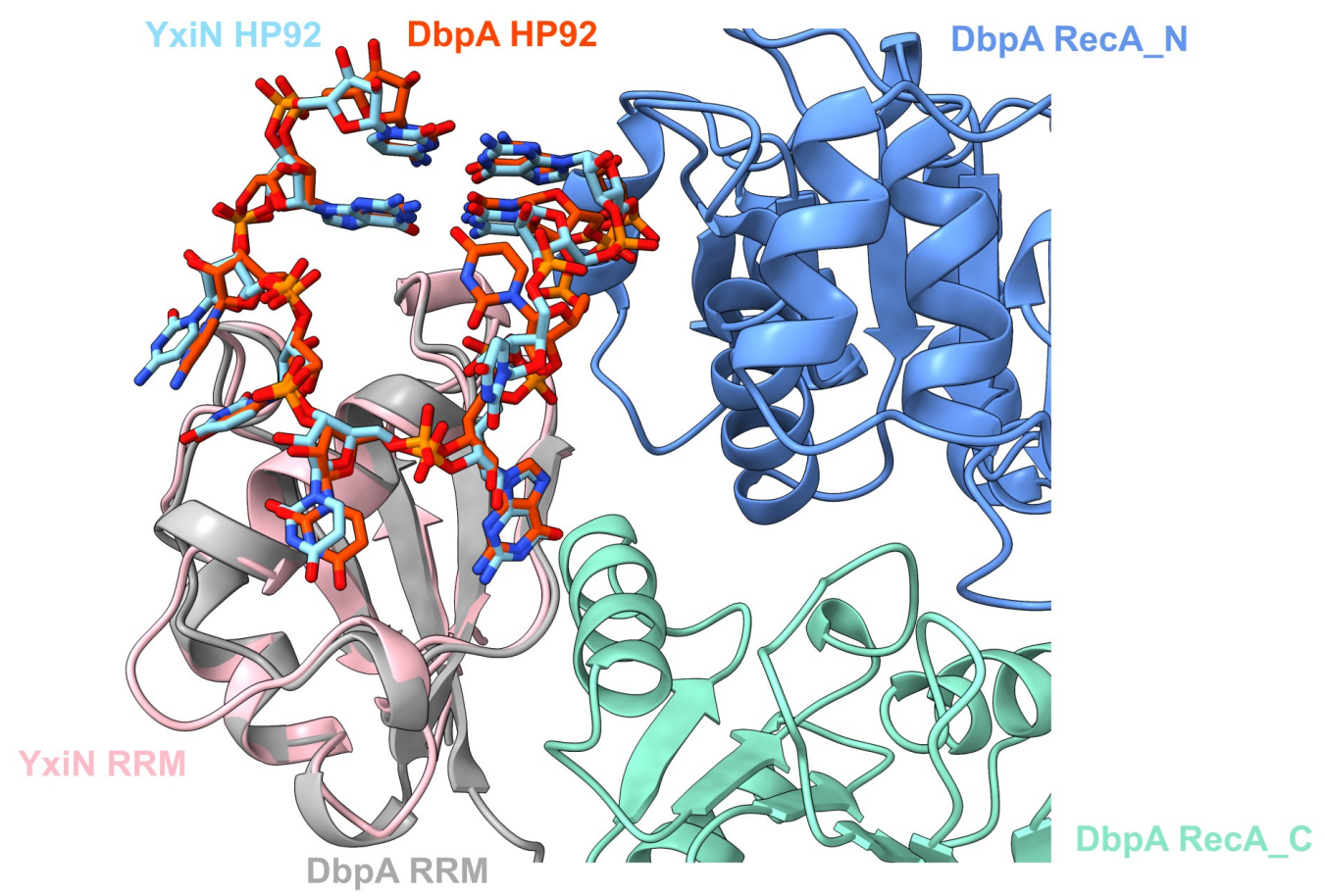

Figure 3 - figure supplement 3: The HP92 RNA binding modes of the RRMs of DbpA and its

\section{Bacillus subtilis homolog YxiN are very similar.}

Overlay of the structures of the YxiN RRM bound to a fragment of the 23S rRNA (PDB ID 3moj)

and the structure of the Hhp-HP92/DbpA/ADP/BeF 3 complex (chains B/G). The RecA_N (DbpA blue), RecA_C (DbpA green) and RRM (DbpA grey, YxiN violett) are shown in ribbon representation. The bound HP92 RNAs are shown in stick representation (DbpA red, YxiN light blue). For clarity only nt 2550-2559 of the rRNA fragment and the corresponding nt of the hp-HP92

794 RNA are shown. 

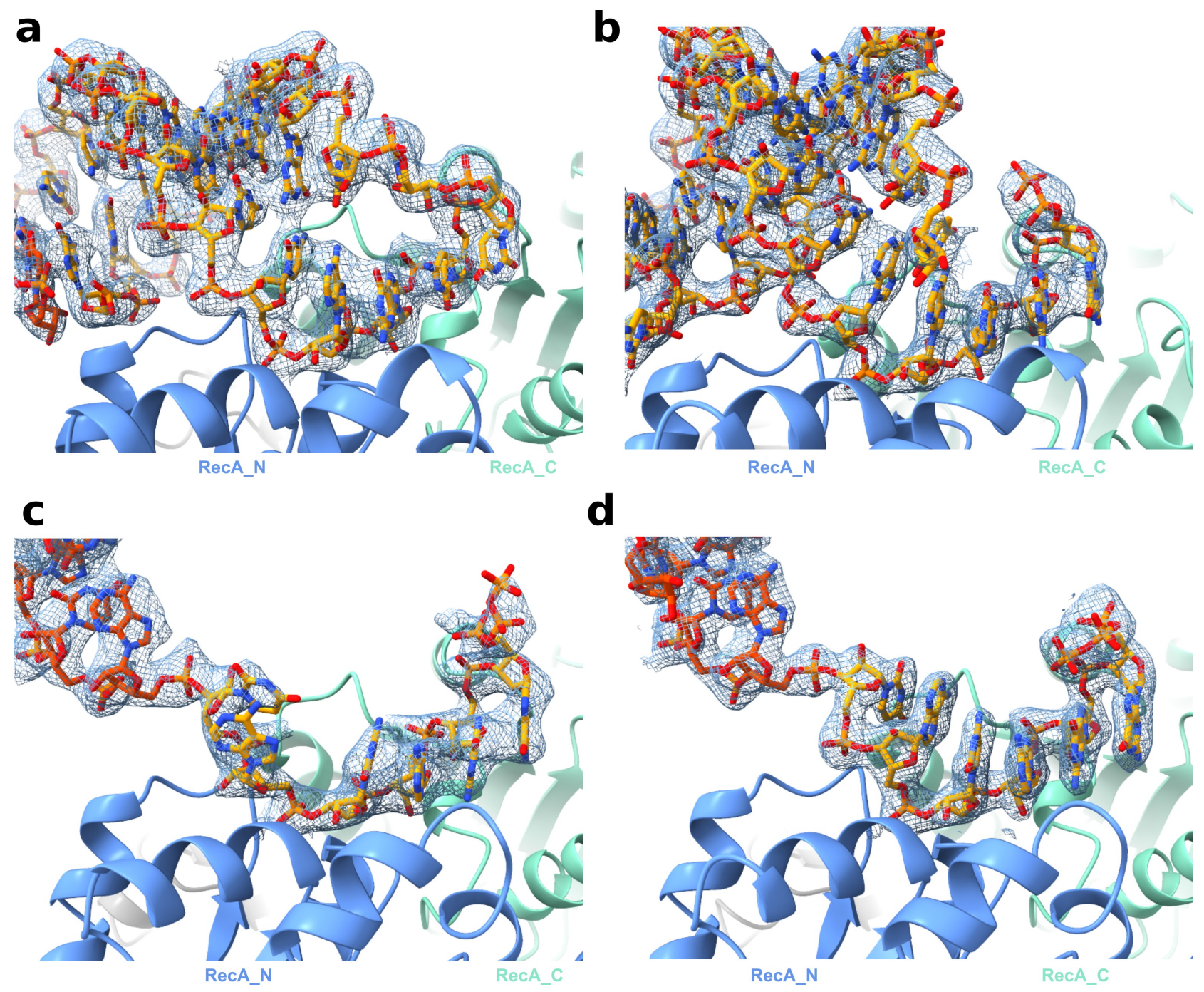

d

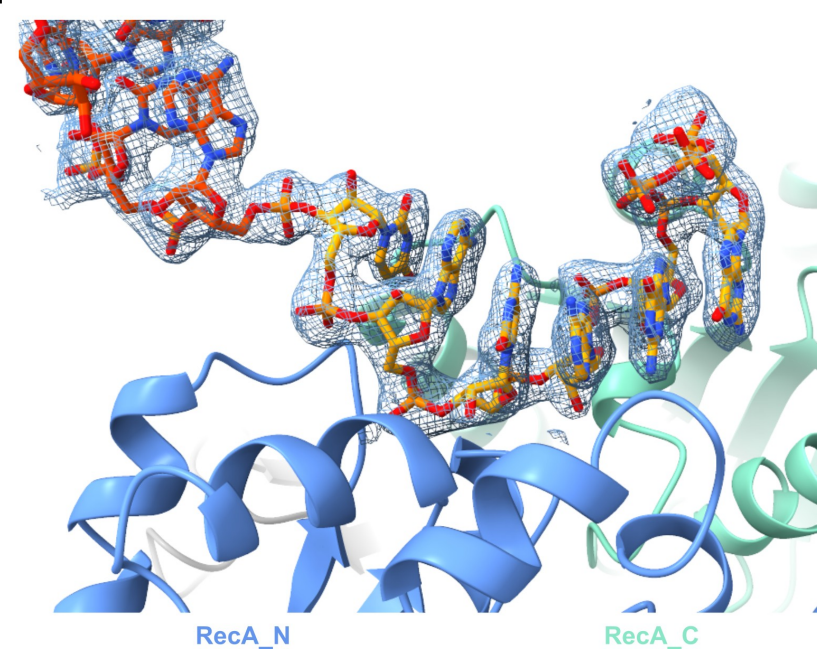

Figure 3 - figure supplement 4: Electron density maps

796 Composite omit 2Fo - Fc maps contoured at $1.0 \sigma$ are shown as a blue mesh for the RNAs depicted in Fig. 3, 4 and 5 of the main text. (a) hp-HP92/DbpA/ADP/BeF 3 complex (chain F). (b) dsHP92/DbpA/ADP/BeF 3 complex (chain D). (c) ss-HP92/DbpA/ADP/BeF 3 complex conformation 1 (chain L). (d) ss-HP92/DbpA/ADP/BeF 3 complex conformation 2 (chain C). 
a

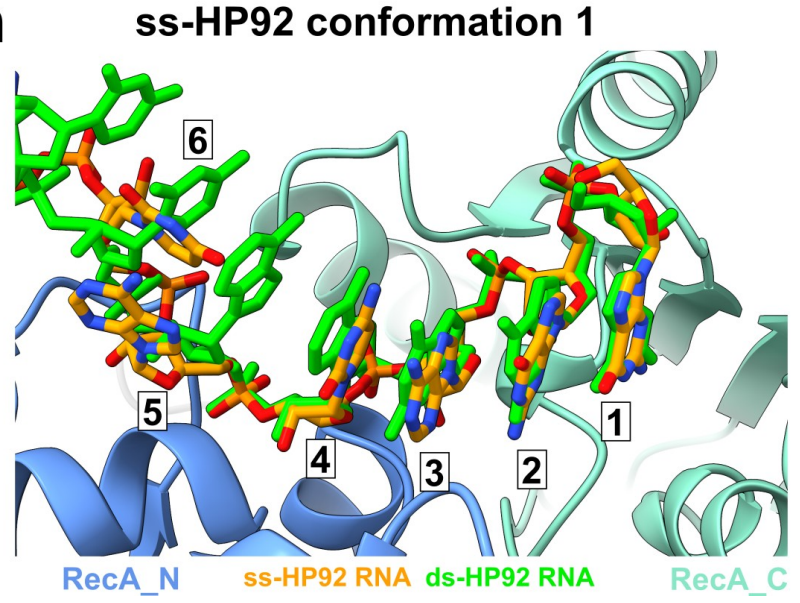

b
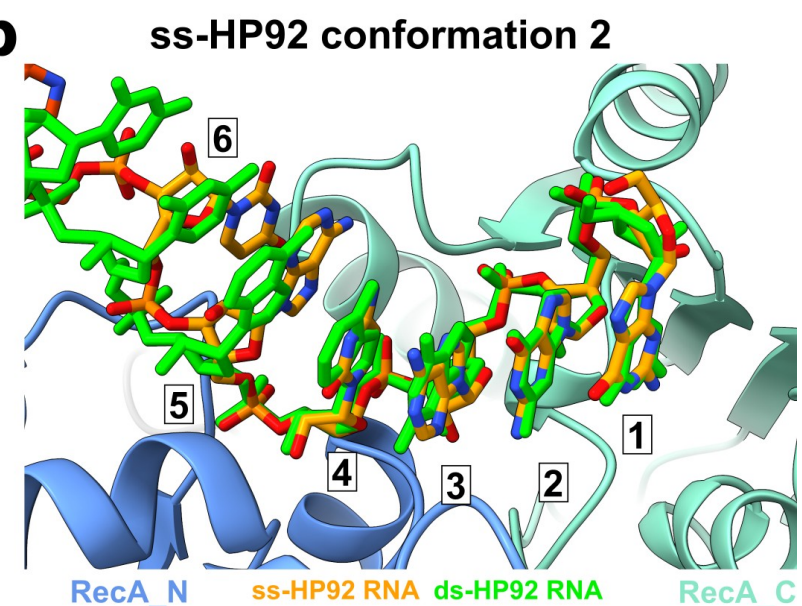

800 Figure 5 - figure supplement 1: The ss-HP92 RNA conformation 2 is more similar to the dsHP92 RNA conformation than ss-HP92 RNA conformation 1

802 Close-ups of the ss-HP92 RNA in (a) conformation 1 (chain L, orange) and (b) conformation 2 (chain C, orange) bound to the active site of DbpA. For comparison the ds-HP92 RNA is shown in

804 green. For clarity the opposite strand that base pairs with nt 4-6 is omitted for ds-HP92 RNA. The nucleotides that interact with the active site are numbered 1-6. The conformation and base orientation of nucleotides 5 and 6 in conformation 2 is more similar to the ds-HP92 RNA conformation compared to conformation 1 , where the bases are flipped by $90^{\circ}$. 
a

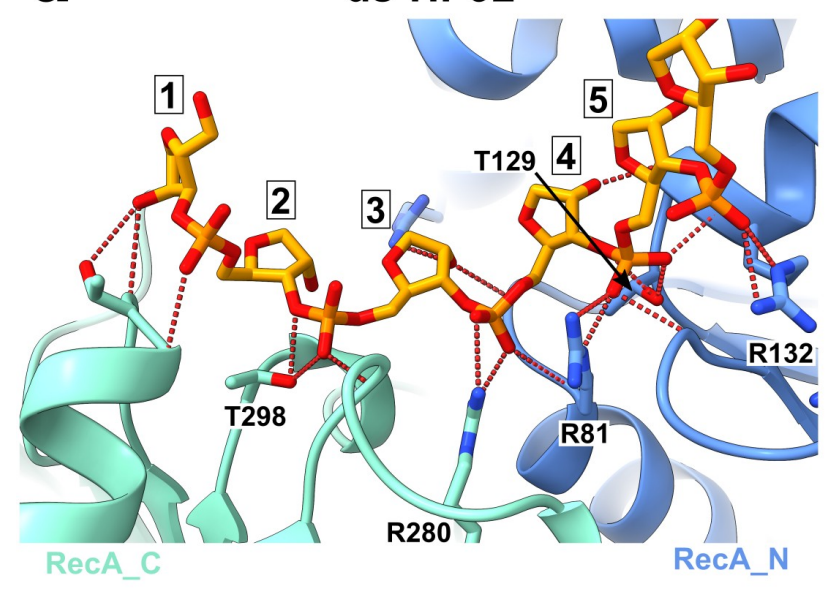

C

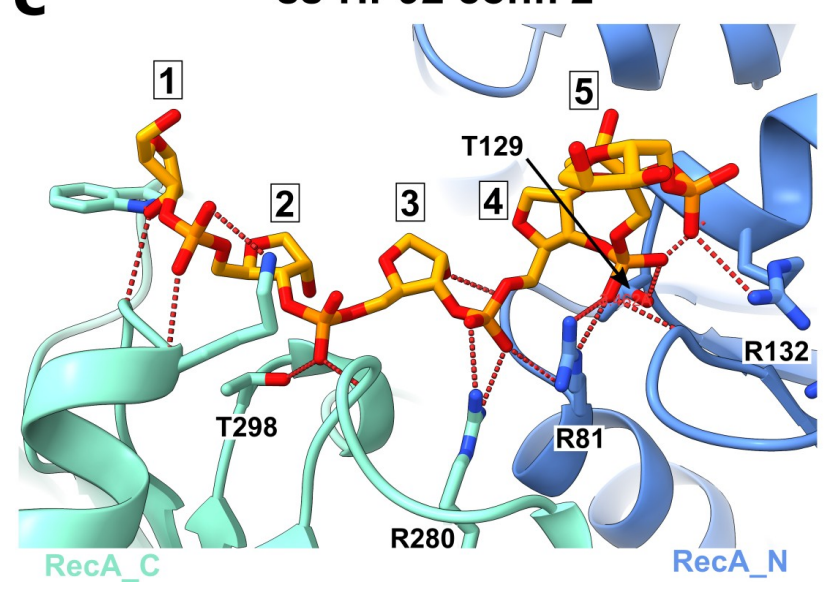

b

ss-HP92 conf. 1
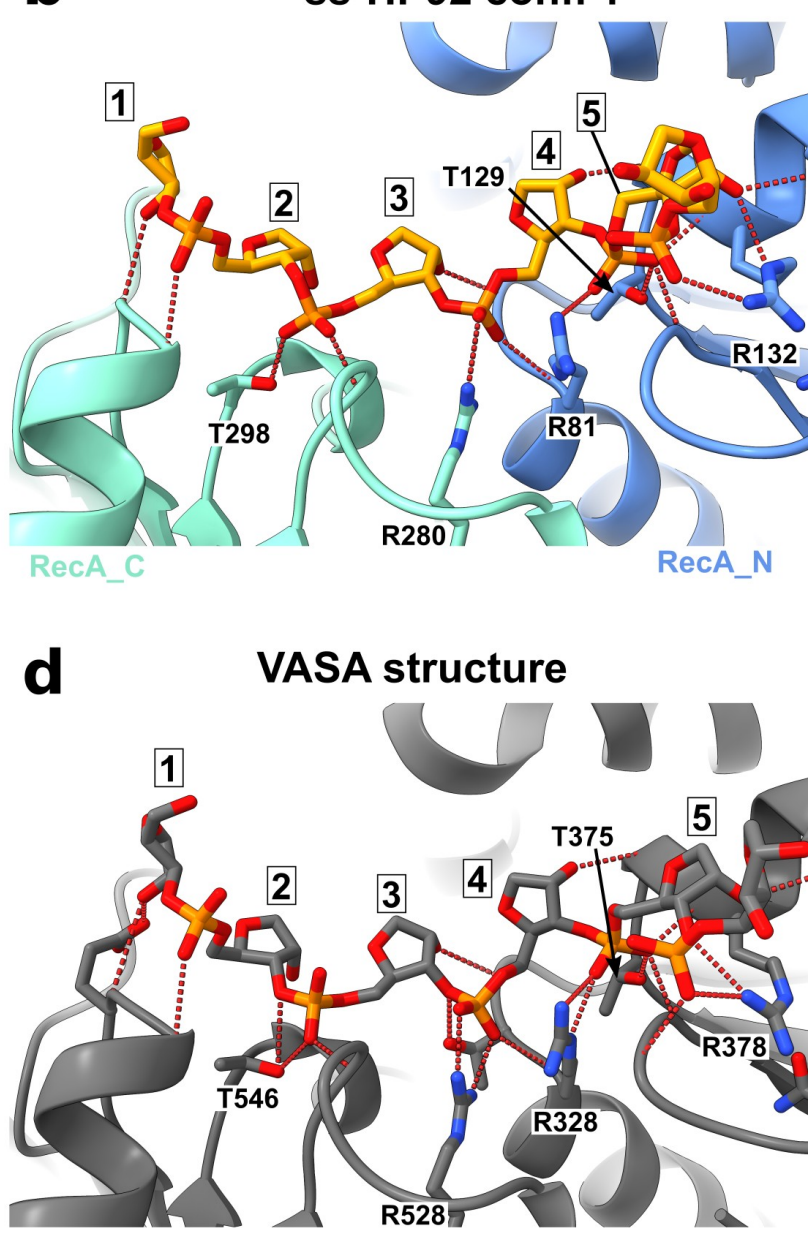

808 Figure 5 - figure supplement 2: Recognition of the RNA backbone of nt 1-5 for DbpA and VASA.

810 Comparison of the recognition of nt in position 1-5 for the DbpA/ds-HP92 complex (chains B/D) (a), DbpA/ss-HP92 complex in conformation 1 (chains L/I) (b) and conformation 2 (chains A/C) (c)

812 and in the VASA/RNA complex (chains D/H) (d). Only the RNA backbone is shown for clarity. Hydrogen bonds between RNA and protein are indicated by by dashed red lines. The nucleotides

814 are numbered 1-5. Protein side chains that contribute important interactions are labeled: R81/R328 are part of the conserved DEAD-box motif Ia (Sengoku et al., 2006), T129/T375 (DbpA/VASA) 816 and R132/R378 (DbpA/VASA) are part of the conserved DEAD-box motif Ib (Sengoku et al., 2006), R280/R528 (DbpA/VASA) are part of the QxxR motif (Sengoku et al., 2006), T546/T298 818 (DbpA/VASA) are part of motif (Sengoku et al., 2006). 
a
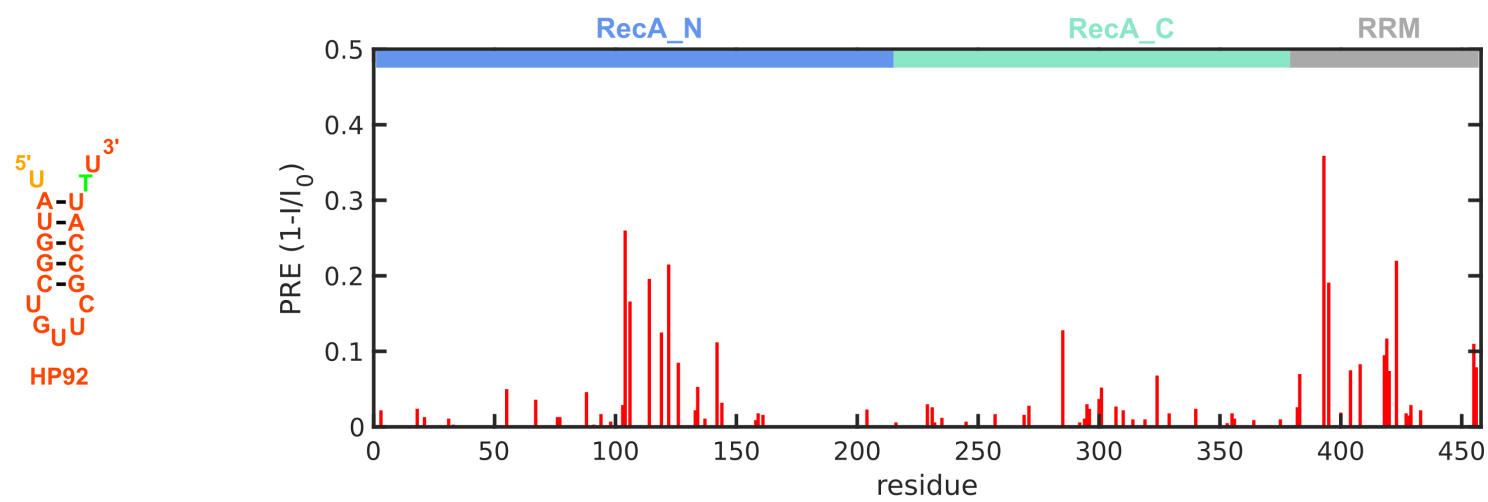

b
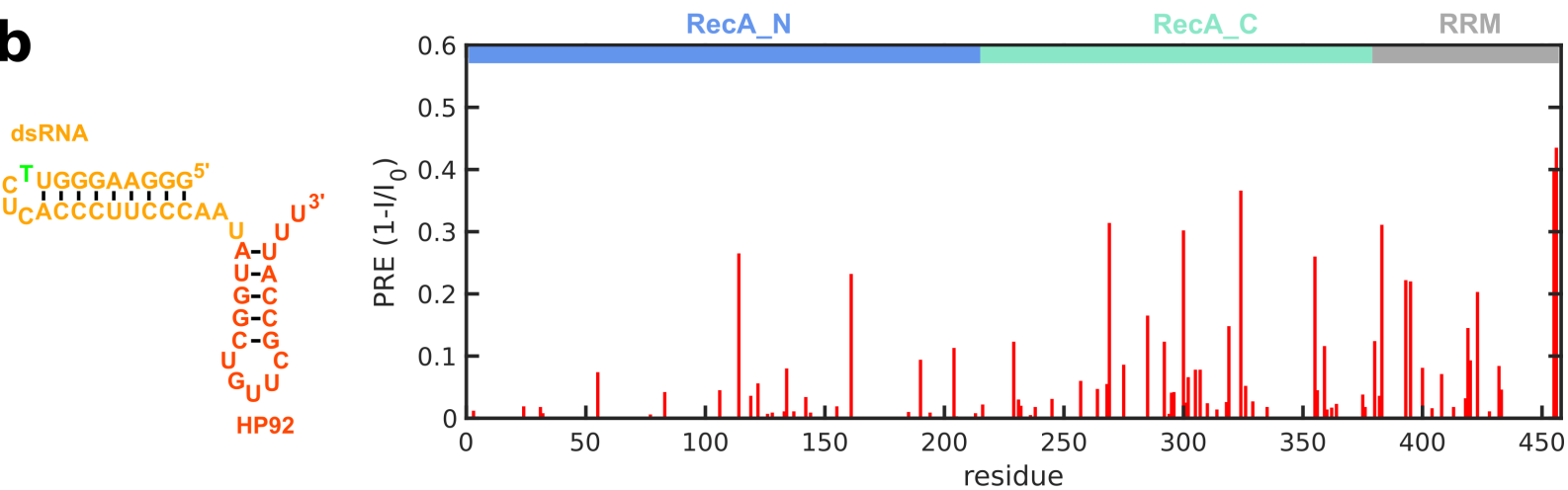

C

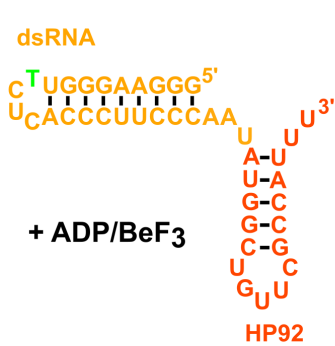

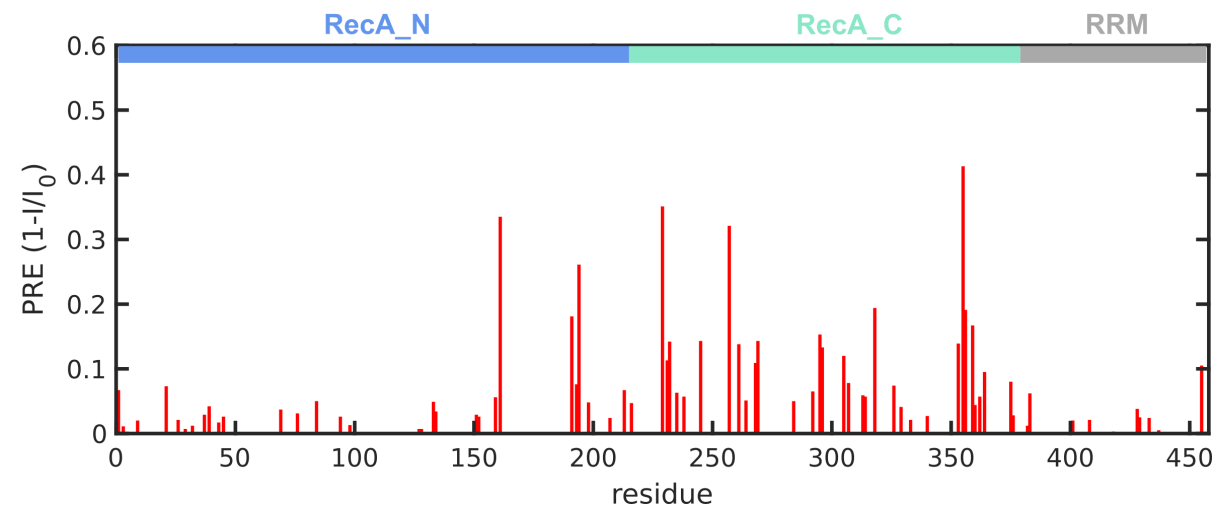

\section{Figure 7 - figure supplement 1: PRE-measurements}

820 (a) HP92 RNA construct used for PRE-measurements (left). T (green) indicates the position of the 4-thiouridine residue that is used to couple the nitroxide spin label to the RNA. The determined

822 PRE values (1-I/I $\left.\mathrm{I}_{0}\right)$ are plotted versus the sequence (right). Increased values indicate the spatial proximity of the spin label. (b) hp-HP92 RNA construct used for PRE-measurements (left). T

824 (green) indicates the position of the 4-thiouridine residue that is used to couple the nitroxide spin label to the RNA. The determined PRE values in the absence of $\mathrm{ADP} / \mathrm{BeF}_{3}\left(1-\mathrm{I} / \mathrm{I}_{0}\right)$ are plotted

826 versus the sequence (right). (c) hp-HP92 RNA construct used for PRE-measurements (left). T (green) indicates the position of the 4-thiouridine residue that is used to couple the nitroxide spin

828 label to the RNA. The determined PRE values in the presence of $A D P / \operatorname{BeF}_{3}\left(1-I / I_{0}\right)$ are plotted versus the sequence (right). 
bioRxiv preprint doi: https://doi.org/10.1101/2022.02.23.481582; this version posted February $23,2022$. The copyright holder for this preprint (which was not certified by peer review) is the author/funder, who has granted bioRxiv a license to display the preprint in perpetuity. It is made available under aCC-BY 4.0 International license.

\section{Appendix}

\section{Appendix 1 - table 1: RNA constructs used in this study}

\begin{tabular}{|c|c|c|c|}
\hline \# & RNA construct & Sequence (5'-3') & $\begin{array}{l}\text { results shown } \\
\text { in Fig. }\end{array}$ \\
\hline 1 & Screening of ATP analogs, 31mer & GAGACGAGACCAAUAUGGCUGUUCGCCAUUU & $2 \mathrm{~A}$ \\
\hline 2 & Screening of ATP analogs, 9mer FI labeled & FI-GGUCUCGUC & $2 \mathrm{~A}$ \\
\hline 3 & Screening of ATP analogs, 9mer unlabeled & GGUCUCGUC & $2 \mathrm{~A}$ \\
\hline 4 & NMR titration/crystallization hp-HP92 & GGGAAGGGUUUCGACCCUUCCCAAUAUGGCUGUUCGCCAUUU & 2B-I,3A-E \\
\hline 5 & NMR titration ss-HP92 & GGACCCUUCCCAAUAUGGCUGUUCGCCAUUU & $2 \mathrm{C}, 2 \mathrm{E}, 2 \mathrm{~F}$ \\
\hline 6 & crystallization ds-HP92 & GGGAACCCUUCCCAAUAUGGCUGUUCGCCAUUUCGGGAAGGGUU & $4 A-D$ \\
\hline 7 & crystallization ss-HP92 & GGACAUAUGGCUGUUCGCCAUUU & $5 A-E$ \\
\hline 8 & ATPase/helicase activity, 8 nt 5' overhang & GAAGAAGAGACGAGACCAAUAUGGCUGUUCGCCAUUU & $6 A-E$ \\
\hline 9 & ATPase/helicase activity, 5 nt 5' overhang & GAAGAGACGAGACCAAUAUGGCUGUUCGCCAUUU & $6 A-D$ \\
\hline- & ATPase/helicase activity, 2 nt 5' overhang & same as \#1 & $6 A-E$ \\
\hline 10 & ATPase/helicase activity, 0 nt 5' overhang & GACGAGACCAAUAUGGCUGUUCGCCAUUU & $6 A-D$ \\
\hline- & ATPase/helicase activity, 9mer FI labeled & same as \#2 & $6 A-E$ \\
\hline- & ATPase/helicase activity, 9mer unlabeled & same as \#3 & $6 A-E$ \\
\hline 11 & HP92 for PRE measurements & UAUGGCUGUUCGCCAU-4TU-U & $7 A$ \\
\hline 12 & hp-HP92 for PRE measurements & GGGAAGGGU-4TU-CUCACCCUUCCCAAUAUGGCUGUUCGCCAUUU & 7B-C \\
\hline
\end{tabular}

838 4TU and Fl indicate a 4-thioruridine residue and a 5' fluorescein label, respectively. 